ORNL/TM-2014/353

\title{
Technology Implementation Plan ATF FeCrAl Cladding for LWR Application
}

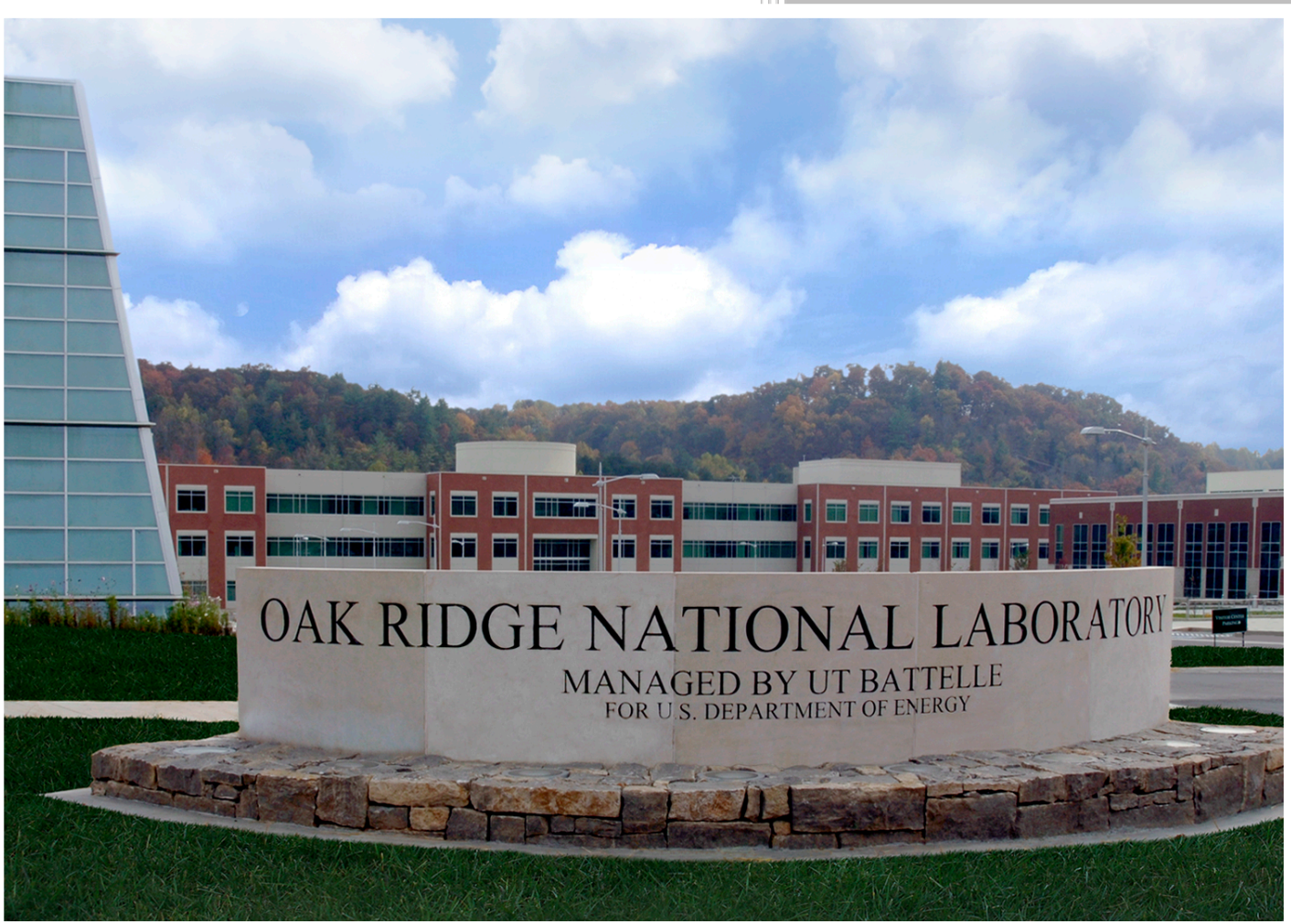
M. Snead
L. Snead
K. Terrani
K. Field
A. Worrall
K. Robb
Y. Yamamoto
J. Powers
S. Dryepondt
B. Pint
X. Hu

\section{May 2015}




\section{DOCUMENT AVAILABILITY}

Reports produced after January 1, 1996, are generally available free via US Department of Energy (DOE) SciTech Connect.

Website http://www.osti.gov/scitech/

Reports produced before January 1, 1996, may be purchased by members of the public from the following source:

National Technical Information Service

5285 Port Royal Road

Springfield, VA 22161

Telephone 703-605-6000 (1-800-553-6847)

TDD 703-487-4639

Fax 703-605-6900

E-mail info@ntis.gov

Website http://www.ntis.gov/help/ordermethods.aspx

Reports are available to DOE employees, DOE contractors, Energy Technology Data Exchange representatives, and International Nuclear Information System representatives from the following source:

Office of Scientific and Technical Information

PO Box 62

Oak Ridge, TN 37831

Telephone 865-576-8401

Fax 865-576-5728

E-mail reports@osti.gov

Website http://www.osti.gov/contact.html

This report was prepared as an account of work sponsored by an agency of the United States Government. Neither the United States Government nor any agency thereof, nor any of their employees, makes any warranty, express or implied, or assumes any legal liability or responsibility for the accuracy, completeness, or usefulness of any information, apparatus, product, or process disclosed, or represents that its use would not infringe privately owned rights. Reference herein to any specific commercial product, process, or service by trade name, trademark, manufacturer, or otherwise, does not necessarily constitute or imply its endorsement, recommendation, or favoring by the United States Government or any agency thereof. The views and opinions of authors expressed herein do not necessarily state or reflect those of the United States Government or any agency thereof. 
Fuel Cycle Research and Development - Advanced Fuels - Advanced LWR Fuels

Technology Implementation Plan ATF FeCrAl Cladding for LWR Application

\author{
M. Snead \\ L. Snead \\ K. Terrani \\ K. Field \\ A. Worrall \\ K. Robb \\ Y. Yamamoto \\ J. Powers \\ S. Dryepondt \\ B. Pint \\ X. $\mathrm{Hu}$
}

Date Published: May 2015

Prepared by

OAK RIDGE NATIONAL LABORATORY

Oak Ridge, Tennessee 37831-6283

managed by

UT-BATTELLE, LLC

for the

US DEPARTMENT OF ENERGY

under contract DE-AC05-00OR22725 



\section{CONTENTS}

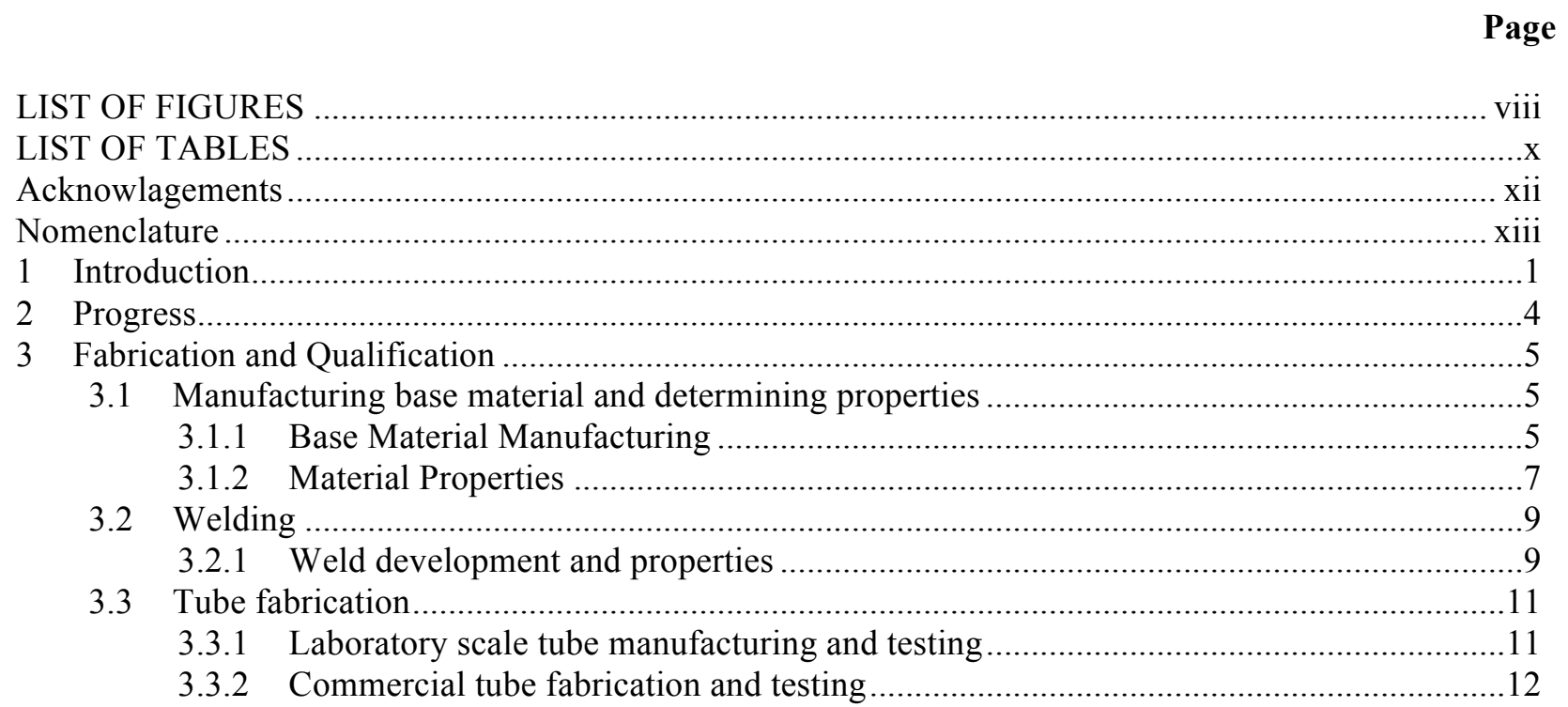

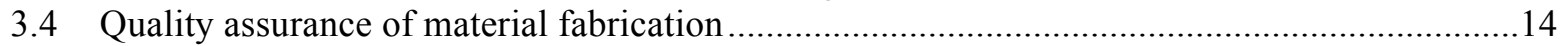

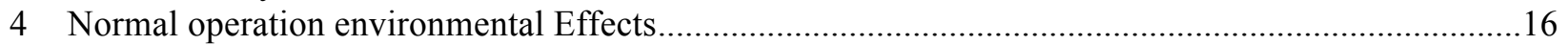

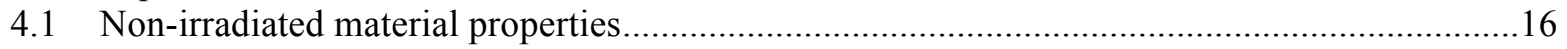

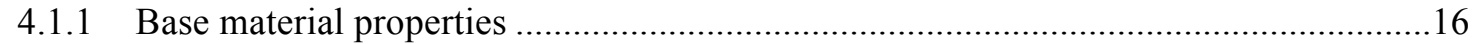

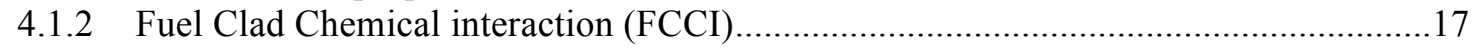

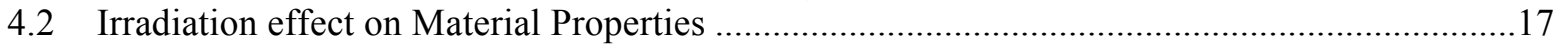

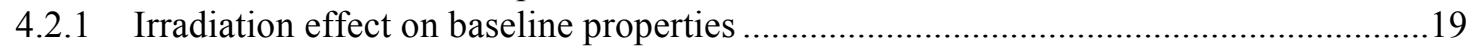

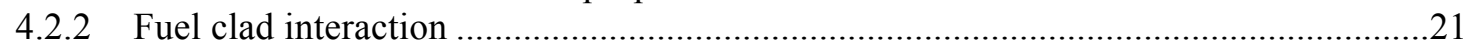

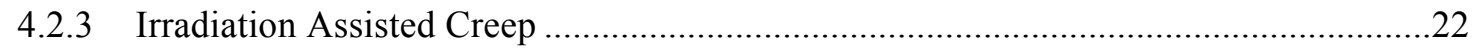

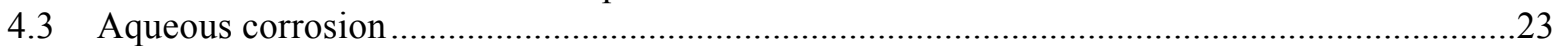

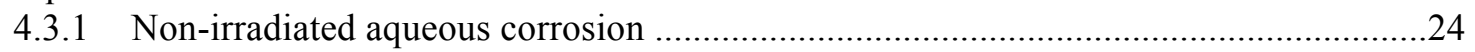

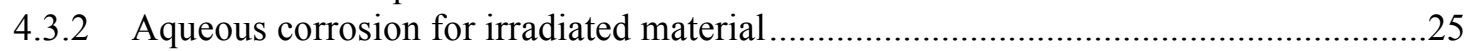

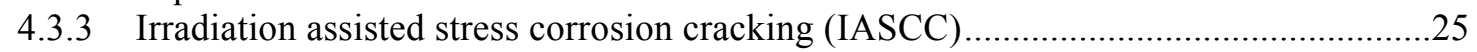

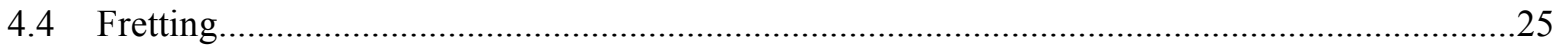

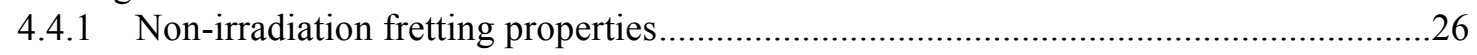

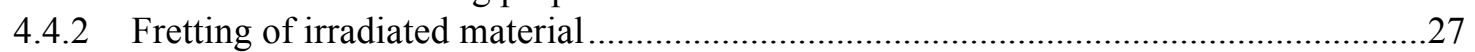

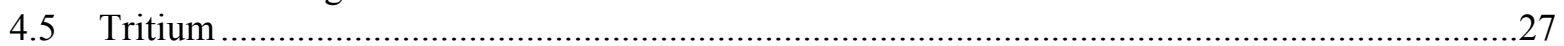

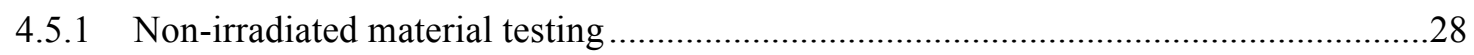

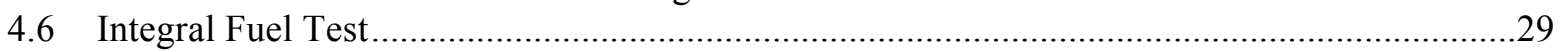

4.6.1 Irradiation of $\mathrm{FeCrAl}$ clad $\mathrm{UO}_{2}$ fuel in the Halden ATF test rig ................................29

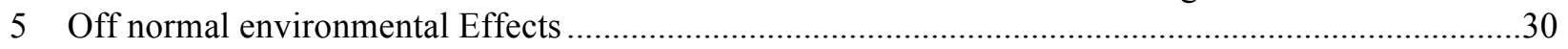

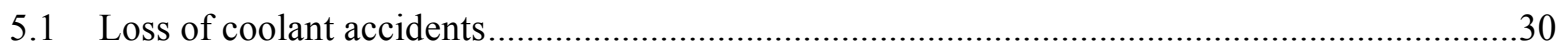

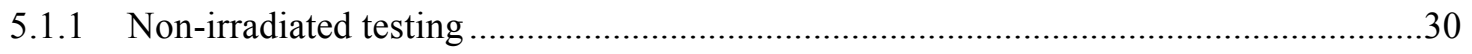

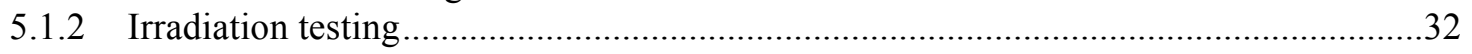

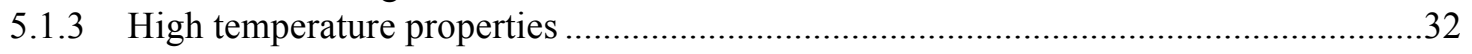

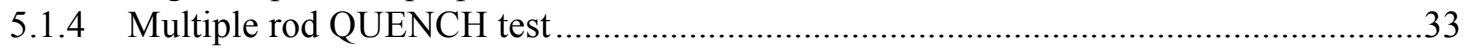

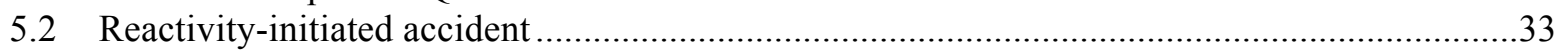

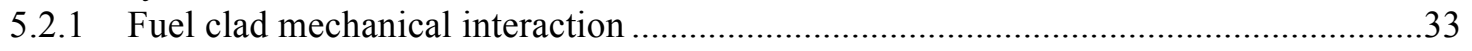

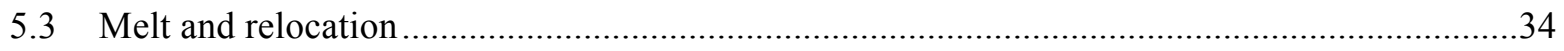

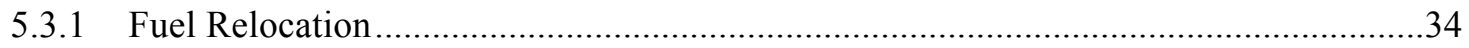

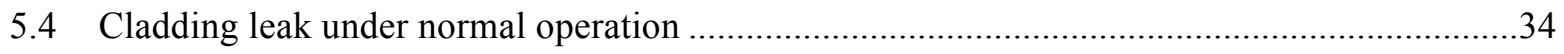




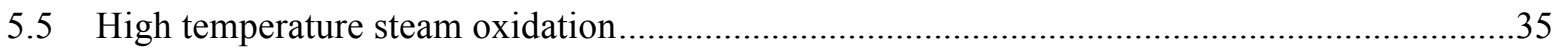

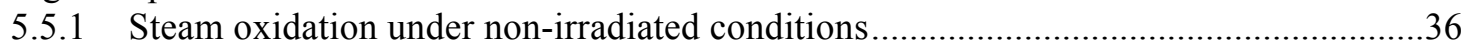

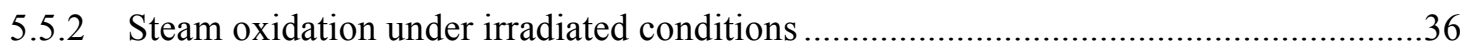

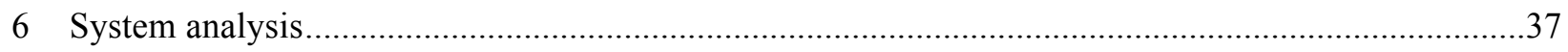

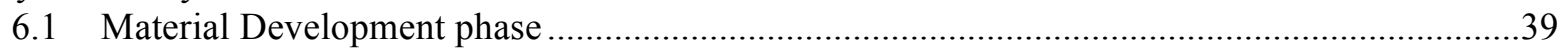

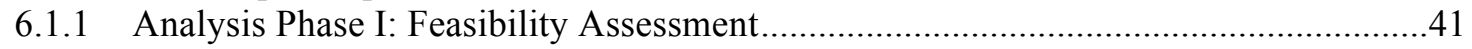

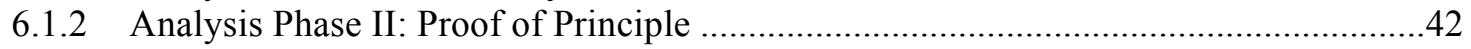

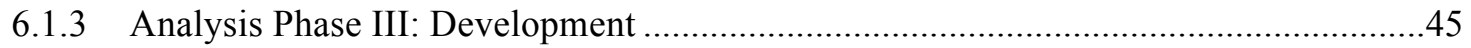

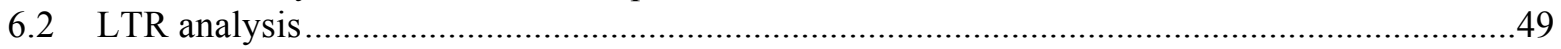

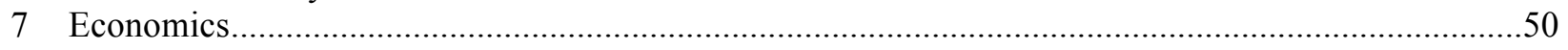

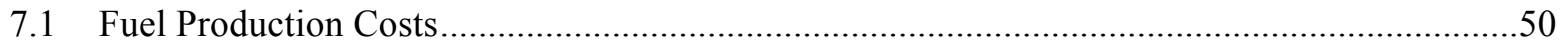

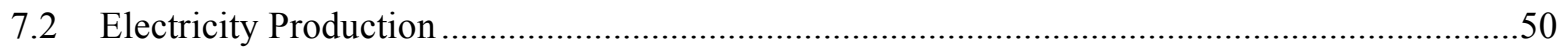

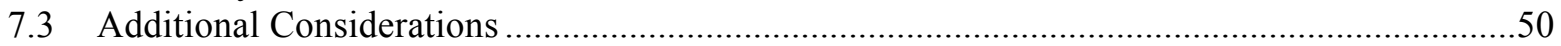

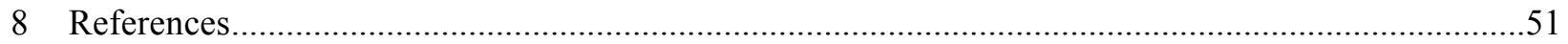





\section{LIST OF FIGURES}

Figure $\quad$ Page

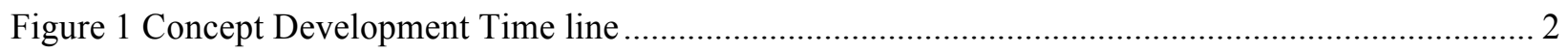

Figure 2 Material Development Schematic for FeCrAl ......................................................................... 3 



\section{LIST OF TABLES}

\section{Table}

Page

Table 1 Temperature and stress conditions for the FeCrAl creep specimens. ...................................... 23

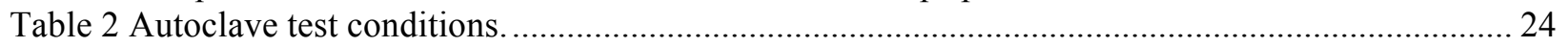





\section{ACKNOWLAGEMENTS}

The aid and technical insight of Jon Carmack at Idaho National Laboratory is gratefully acknowledged. A number of other Advanced Fuels Campaign participants from Idaho National Laboratory and Los Alamos National Laboratory also contributed to this document. The work presented in this paper was supported by the Advanced Fuels Campaign of the Fuel Cycle R\&D program in the Office of Nuclear Energy, US Department of Energy. 


\section{NOMENCLATURE}

$\mathrm{Al}$ - Aluminium

AOO - Anticipated Operating Occurrence

ASME - American Society of Mechanical Engineers

ATF - Acident Tolerant Fuel

ATF-1 - Accident Tolerant Fuel experiment 1 Irradiation of miniaturized rodlets at ATR

ATR - Advance Test Reactor

BCC - Body-centered cubic

BDBA - Beyond design basis accident

BE - Best estimate

BWR - Boiling water reactor

$\mathrm{C}-$ Carbon

$\mathrm{CC}+\mathrm{CI}-$ Core components and chemical interactions

$\mathrm{Cr}-\mathrm{Chromium}$

DBA - Design basis accident

DBTT - Ductile-brittle transition temperature

DCS - Differential scanning calorimetry

DNB - post-departure from nuclear boiling

Dpa - Displacement per atom

FCC - Face-centered cubic

FCCI - Fuel Clad Chemical Interaction

FCMI - Fuel Clad Mechanical Interaction

FCRD - Fuel Cycle Research and Development

FCT - Fuel cycle technology

$\mathrm{Fe}-$ Iron

FIV - Flow-induced vibration

FP - Thermo-mechanical fuel performance

$\mathrm{ft}-$ Feet

FTC - Fuel temperature coefficient

FY - Finacial year ranging from October to September

g- gram

GTRF - Grid-to-rod fretting

GWd - Gigawatt day

Halden - Halden Reactor

Hf - Hafnium

HFIR - High flux isotope reactor

$\mathrm{HTF}$ - High temperature furnace

HWC - Hydrogen water chemistry

IASCC - Irradiation assistant stress corrosoin cracking

IFBA - Integral Fuel Burnable Absorber

$\mathrm{kgU}$ - kilogram Uranium

KIT - Karlsruhe Institute of Technology

$\mathrm{lb}-$ pound

LOCA - Loss of coolent accident

LT - Long term

LTR - Lead Test Rod

LTSBO - Long-term station black out

LWR - Light Water Reactor 
$\mathrm{m}-$ meter

MCPR - Minimum critical power ratio

MDNBR - Minimum departure from nuclear boiling ratio

Mo - Molybdenum

$\mathrm{MPa}$ - Mega-pascal

MTC - Moderator temperature coefficient

MWd - Mega-watt day

$\mathrm{Nb}-$ Niobium

Neutronics - Reactor physics

NFA - Nano-featured alloy

$\mathrm{NO}$ - Normal Operation

NRC - Nuclear Regulatory Commision

NWC - Normal water chemistry

$\mathrm{O}$ - Oxigen

${ }^{\circ} \mathrm{C}$ - degree Centigrade

ODS - Oxide dispersion strengthened

ORNL - Oak Ridge National Laboratory

PCI - Pellet Clad Interaction

PCI - Pellet clad interaction

PCMI - Pellet clad mechanincal interaction

PCMI - Pellet Cladding Mechanical Interaction

$\mathrm{PF}$ - Peaking factor

PIE - Post irradiation examination

PWR - Pressurized water reactor

QA - Quality Assurance

QAP - Quality Assurance Plan

QAPD - Quality Assurane Plan Document

R\&D - Research and development

RAFM - Reduced activation feretic/martensitic (steel)

RIA - Reactivity insertion accident

RIS - Radiation induced segregation

RT - Room temerature

SA - Severe accident

SATS - Severe accident test station

SBLOCA: small break loss of coolant accident

SBO - Station blackout

$\mathrm{Si}-$ Slilicon

ST - Short term and

STA - Simultaneous Thermal Analyzer

STSBO - Short-term station blackout

$\mathrm{T} / \mathrm{H}$ - Thermal-hydraulics

$\mathrm{Ti}$ - Titanium

TIG - Tungsten inert gas (welding)

TIP - Technology Implimentation Plan

TRL - Technology readyness leavel

$\mathrm{U}$ - uranium

VIM - Vacuum induced melt

WABA - Wet Annular Burnable Absorbers

Wt.\% - weight percentage

$\mathrm{Y}-\mathrm{Yttrium}$

$\mathrm{Zr}-$ Zirconium 



\section{INTRODUCTION}

This document is to provide a technology implementation plan (TIP) for the development of a nucleargrade FeCrAl alloy for fuel cladding in Light Water Reactors (LWRs). The purpose of this TIP is not design and licensing work to support Lead Test Rod (LTR) insertion into a commercial Light Water Reactor (LWR) in the US but rather to provide confidence in the ATF FeCrAl clad concept before significant investments of time and money are made for licensing efforts. The results from these testing and analyses should be documented and shared with the licensee to support their licensing analyses, but LTR analysis would need to be performed separately by the reactor licensee in conjunction with the vendor using approved methodologies and codes and submitted to the Nuclear Regulatory Commission (NRC) by the licensee of the reactor in question.

Front-end and back-end issues such as fuel storage in spent fuel pools or dry storage, repository impacts, uranium mining, fuel fabrication, fuel transportation, fuel handling, impacts on reprocessing if desired, etc. will not be addressed in this plan. These fuel cycle impacts will need to be analyzed and addressed at some point.

The development of nuclear-grade ATF FeCrAl alloys targets a new, metal-base structural material for nuclear fuel cladding, substituting for zirconium alloys, that exhibits greatly improved accident tolerance, including good mechanical properties in a wide temperature range as well as oxidation and irradiation resistance under normal and transient operating conditions. ATF FeCrAl alloys will be selected based on their excellent oxidation resistance in high temperature steam environments up to $1475^{\circ} \mathrm{C}$ (provided by the sufficient amounts of $\mathrm{Cr}$ and $\mathrm{Al}$ additions), compared to the industry standard zirconium alloys which would not have such good temperature oxidation resistance in steam. This is the key for enhancing safety margins under severe accident conditions by limiting the heat and hydrogen production, which occurs when the fuel cladding reacts with steam during a severe accident. With superior high temperature strength compared to zirconium alloys, utilization of this class of alloys is expected to enhance burst margins during design basis accident scenarios and potentially for conditions extending beyond those limits. The current alloy design strategy is focused on developing a nuclear-grade material that exhibits comparable or superior behavior under normal operating conditions (at $320^{\circ} \mathrm{C}$ in pressurized water environments) when compared with today's commercial Zr-based alloys. Once this step is accomplished on the laboratory scale, a commercial-base processing route for thin-wall tube production will be developed to enable deployment of this class of alloys as nuclear fuel cladding.

A concept development timeline is given in Figure 1. This document only focuses on the development of FeCrAl clad in combination with $\mathrm{UO}_{2}$ fuel.

Figure 2 gives the material development schematic for ATF FeCrAl in more detail. 


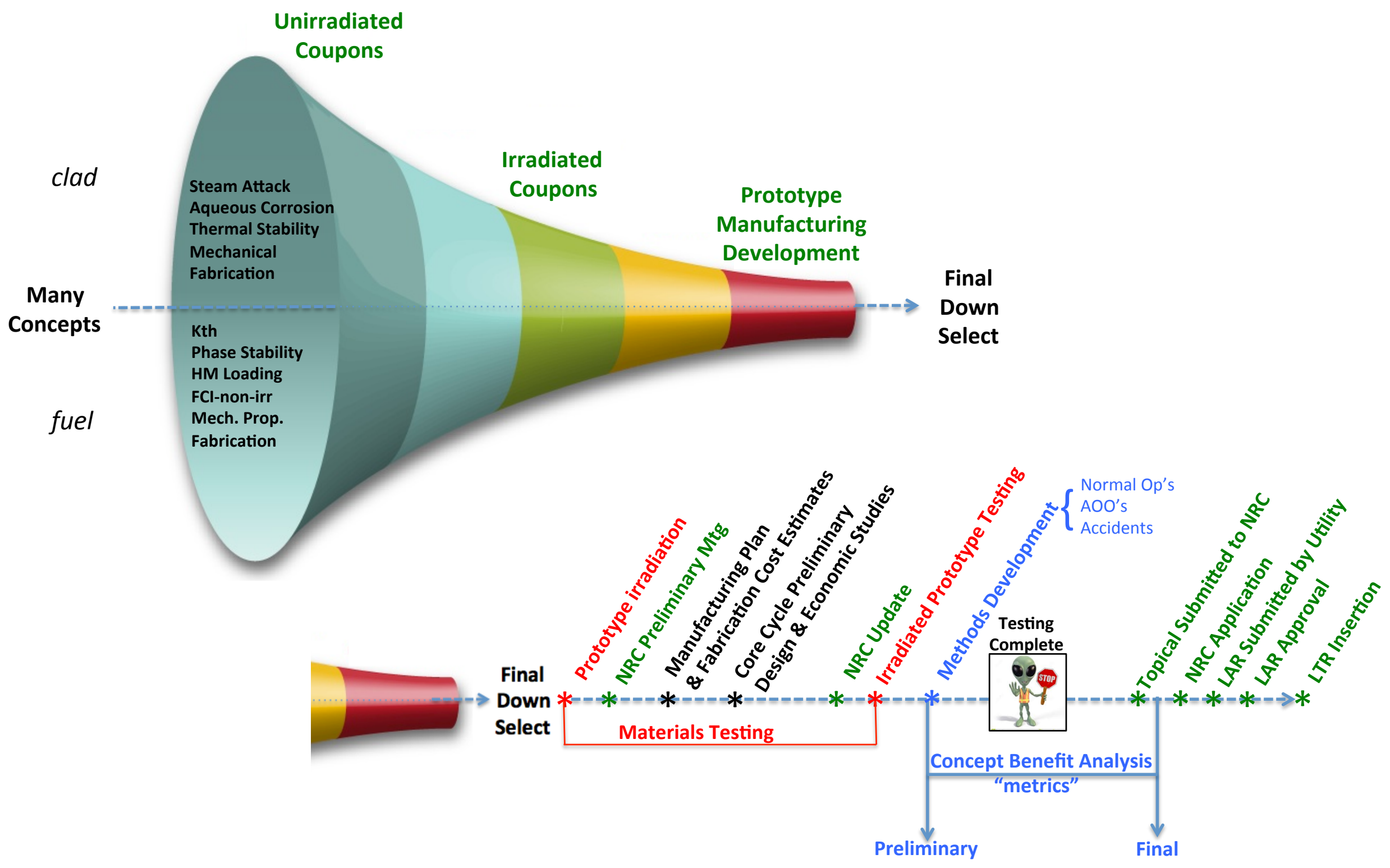

Figure 1 Concept Development Time line 
Normal Environmental compatibility test

1.1.1. material properties (Mech., micr)

1.1.2. tritium migration?

1.1.3. aqueous corrosion

1.1.4. fretting

1.2.1. irradiated material properties (Mech., micr)

1.2.2. irradiated material tritium migration

1.2.3. irradiated material aqueous corrosion

1.2.4. irradiated material fretting

1.2.5. IASCC

1.2.6. FCCI/MI

1.2.7. in pile creep (Halden)

1.2.8 Fuel irradiation test (ATR, Halden)

\begin{tabular}{|c|c|}
\hline $\begin{array}{l}\text { Pick various } \\
\mathrm{Cr} / \mathrm{Al} \text { ratios }\end{array}$ & $\begin{array}{l}\text { Accident Environmental compatibility test } \\
\text { 2.1.1. High temperature properties (mech., micr) } \\
\text { 2.1.2. Steam oxidation }\end{array}$ \\
\hline$\nabla$ & 2.1.3. Burst test \\
\hline $\begin{array}{c}\text { Small lab } \\
\text { scale heat fab. }\end{array}$ & $\begin{array}{l}\text { 2.2.1. irradiated material High temp } \\
\text { properties (Mech., micr) }\end{array}$ \\
\hline 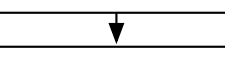 & $\begin{array}{l}\text { 2.2.2. irradiated material steam oxidation } \\
\text { 2.2.3. irradiated material burst test }\end{array}$ \\
\hline Gen. I & 2.2.4. irradiated material $\mathrm{FeCrAl} / \mathrm{UO} 2$ transients \\
\hline
\end{tabular}

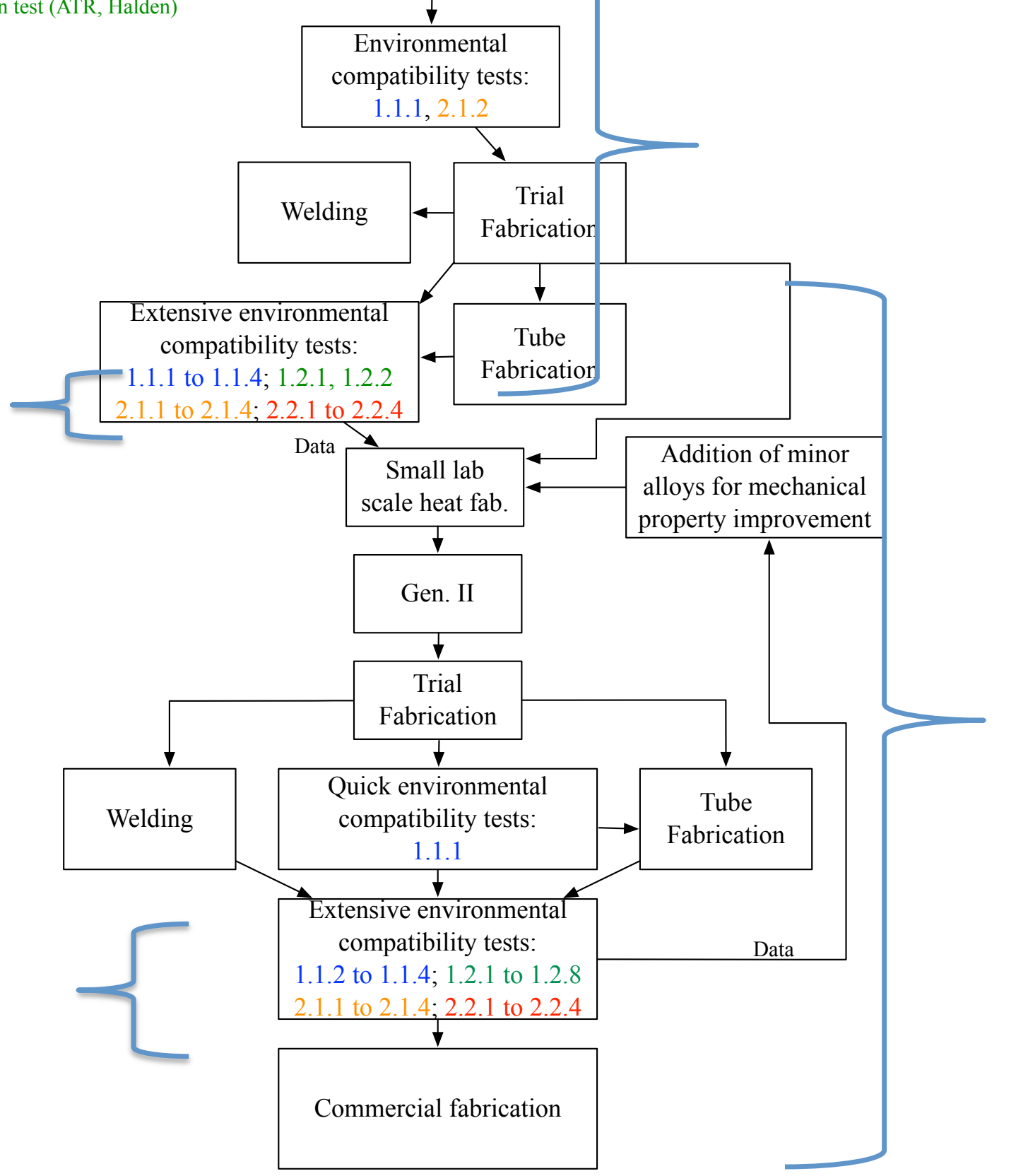

Figure 2 Material Development Schematic for FeCrAl 


\section{PROGRESS}

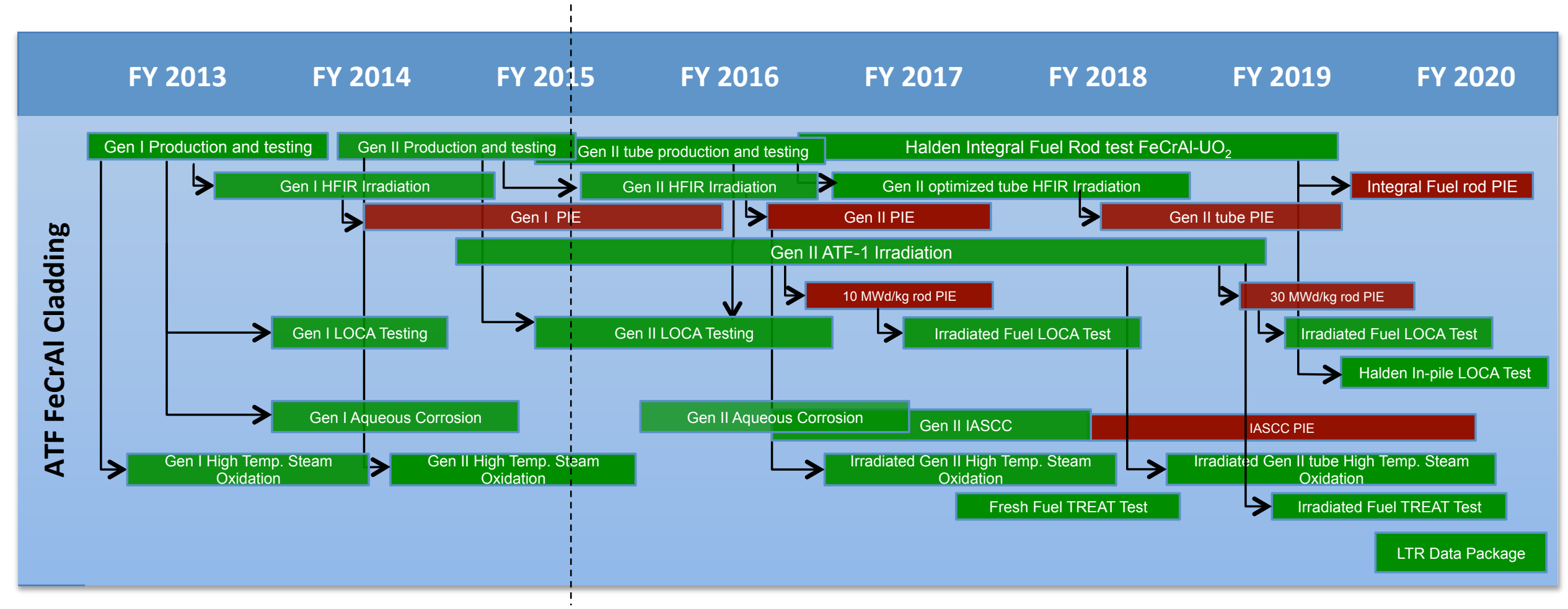

A notable accomplishment in FY14 was determination of the effect of major alloying elements (i.e. $\mathrm{Cr}$ and $\mathrm{Al}$ ) on high-temperature steam oxidation behavior of $\mathrm{FeCrAl}$ alloys. In FY15, the effect of major alloying elements on corrosion behavior of these alloys in LWR coolant environments was examined. Also, in the same year, neutron irradiation and Post Irradiation Examination (PIE) of miniature FeCrAl tensile bars was completed to map out the effect of major alloying elements on the mechanical properties after irradiation. 


\section{FABRICATION AND QUALIFICATION}

\subsection{MANUFACTURING BASE MATERIAL AND DETERMINING PROPERTIES}

The first efforts specifically targeted to find optimized alloy compositions of the nuclear-grade $\mathrm{FeCrAl}$ alloys for LWR fuel cladding with accident tolerance, including evaluation of various properties of the candidate alloys such as fabricability, oxidation resistance, mechanical properties, weldability, and irradiation resistance.

Evaluation of model FeCrAl alloys was performed as "Phase I" (Generation I), which focused on the mechanical and/or functional properties such as, oxidation resistance, fabricability, and weldability, as a function of the major alloying elements.

It is hypothesized that the higher chromium $(\mathrm{Cr})$ additions in the range of 10-22 wt. \% would be better for corrosion resistance or and oxidation resistance to support the stability of the alumina-scale over a wide temperature range, although it would increase potential embrittlement of the materials at relatively lower temperatures due to the formation of $\sigma-\mathrm{FeCr}$ or $\alpha^{\prime}-\mathrm{Cr}$ phases. The higher aluminum (Al) additions would also be beneficial for the oxidation resistance, especially at elevated temperatures, but it may raise the ductile-brittle transition temperature (DBTT) and the work hardenability which and could affect the room temperature fabricability.

Based on the results in Phase I, a range of candidate $\mathrm{FeCrAl}$ alloy compositions will be selected as base materials for further optimization of the alloys as Phase II or so-called "Generation II ATF FeCrAl alloys." The effort will include minor alloying additions through guidance of computational thermodynamic tools for improved strengths together with sufficient oxidation resistance at elevated temperatures, as well as a good fabricability for potential commercial tube fabrication. Higher strength alloys are of particular interest as thinner clad is needed to offset the neutronic penalty of using a FeCrAl based clad.

Laboratory heats as well as commercially fabricated heats will be used for the property evaluation as a function of not only the alloy compositions but also the fabrication processes.

Selected materials will be further evaluated for trial tube fabrication at commercial tube manufacturers.

Development of a 1st generation, nuclear grade oxide dispersion strengthened (ODS) FeCrAl alloy for high performance, thin walled accident tolerant fuel cladding will also be pursued. A high strength, high oxidation resistance alloy will facilitate development of a thin walled cladding with similar performance as current cladding. Fine stable oxide dispersion may also improve the radiation tolerance of $\mathrm{FeCrAl}$ alloys. Thermodynamic calculations and results from the wrought ATF FeCrAl characterization will be used to guide composition selection. Materials processing optimization and quantification of mechanical properties and oxidation resistance will be the initial goals as well as investigating the joining of this material. The role of solid solution strengthening (e.g. Mo additions) on mechanical properties will be investigated.

\subsubsection{Base Material Manufacturing}

\subsubsection{ATF FeCrAl}

Design strategy of the ATF FeCrAl alloys includes improved strength and promising oxidation resistance to maintain the soundness of the materials over a wide temperature range from service temperature $\left(\sim 320^{\circ} \mathrm{C}\right.$ ) to potential accident condition (up to $\sim 1300-1400^{\circ} \mathrm{C}$ ), suitable for substitution of currently used 
zirconium alloys. The ATF FeCrAl alloys should also have a good fabricability since the final cladding tube products will need to be fabricated through conventional industrial equipment (extrusion, drawing, etc.) in commercial manufacturers. Thermal stability is also the key for the materials to retain the mechanical properties during long time service or potential accident situation after certain hours/years of service.

The Generation II ATF FeCrAl alloys will be designed with solid-solution strengthening and/or secondphase precipitate strengthening via minor alloying additions, through a guidance of computational thermodynamic tools. Solution hardening is expected from the Mo addition. Potential second-phases to be introduced will be $\mathrm{M}_{23} \mathrm{C}_{6}$ (M: mainly $\mathrm{Cr}$ ), $\mathrm{MC}\left(\mathrm{M}\right.$ : mainly $\mathrm{Nb}$ ), and Laves-Fe ${ }_{2} \mathrm{M}$ (M: mainly Mo and $\mathrm{Nb}$ ). Multiple candidate "model" alloy compositions, which exhibit single- or multi second-phase formation, will be down-selected based on the phase prediction, and then the lab-heats with 600-700g will be fabricated through arc-melting and drop-casting at ORNL. After homogenization heat treatment, hot/warm-rolling and annealing will be applied with various conditions in order to simulate potential tube manufacturing processes, either hot-extrusion or warm-drawing.

\section{Activities and Milestones}

FY13

- Manufacture Generation I ATF FeCrAl (2013-2014) (COMPLETE)

- Test base material Generation I ATF FeCrAl (2013-2014) (Sections 3.1.2.1, 5.5.1) (COMPLETE)

- Manufacture Generation II ATF FeCrAl 2013-2016 (IN PROGRESS)

FY 14

- Test base material Generation II ATF FeCrAl (2013-2016) (Sections 3.1.2.1, 4, 5) (IN PROGRESS)

- Continue manufacture and optimization of Generation II ATF FeCrAl (2013-2016)

- M3FT-14OR0202232 Signify Completion of Second Generation ATF FeCrAl Alloy Fabrication 06/11/2014 COMPLETE

- M2FT-14OR0202231 Report on the development of 2nd generation ATF FeCrAl alloys 09/30/2014 COMPLETE

FY15

- Continue optimization and testing of Generation II ATF FeCrAl (2014-2016)

FY16

- Complete optimization of Generation II ATF FeCrAl before large scale tube production (20152016)

- $\quad$ M2 Final Report on Optimized $2^{\text {nd }}$ Generation ATF FeCrAl Alloy 4/20/2016

- Continue testing of optimized Generation II ATF FeCrAl (2016-2022) (Sections 4 and 5)

\subsubsection{ATF ODS FeCrAl}

Development of the 1st generation ATF ODS FeCrAl alloy will also be pursued for potential high performance cladding. It includes the fabrication of selected ODS alloys, starting from the powder preparation, with the candidate alloy compositions based on the Phase I study in FY13. The ball milling and extrusion conditions (milling duration and speed, extrusion ratio and temperature...) will be optimized to improve the intermediate and high temperature tensile properties of the alloys without affecting the high temperature steam oxidation resistance. Further optimization of the high temperature mechanical properties will be conducted via minor alloying addition such as $\mathrm{Zr}$ and Hf. Information from Generation I and II of ATF FeCrAl will also be used as input to Generation II ATF ODS FeCrAl.

As for the wrought $\mathrm{FeCrAl}$ alloy, hot/warm rolling and high temperature annealing will be conducted to simulate potential tube manufacturing processes. Warm rolling $\left(<400^{\circ} \mathrm{C}\right)$ would be preferable because of 
the upper limit temperature of conventional die materials, but the outstanding tensile properties of ODS alloys may require processing the alloys at higher temperatures $\left(600-900^{\circ} \mathrm{C}\right.$ range). Because of the excellent microstructure stability of these alloys up to $\sim 900^{\circ} \mathrm{C}$, the alloy properties should only be moderately affected by high temperature tube processing.

Activities and Milestones

FY 14

- Manufacture Generation I ATF ODS FeCrAl (2013-2014) (COMPLETE)

- M3FT-14OR0202272 Report on fabrication of initial heats of dispersion strengthened FeCrAl with and without Mo additions 4/30/2014 (COMPLETE)

- Test base material Generation I ATF ODS FeCrAl (2013-2015) (section 3.1.2.2, 5.5.1)

- M2FT-14OR0202271 Complete report on production and properties of ORNL ATF (ODS) FeCrAl candidate alloys 09/02/2014 (COMPLETE)

FY 15

- Continue Testing of Generation I ATF ODS FeCrAl (2014-2015)

- M3FT-15OR0202281 Report on progress and properties of first generation ODS FeCrAl alloys for ATF cladding 9/18/2015

- Manufacturing of Generation II ATF ODS FeCrAl (2015-2016)

FY16

- Testing of Generation II ATF ODS FeCrAl (2016-2017) (3.1.2.2, 5.5.1)

- Optimization of Generation II ATF ODS FeCrAl for thin tubing (2016-2017)

FY17

- $\quad$ Testing of optimized Generation II ATF ODS FeCrAl (2017-2018) (3.1.2.2, 5.5.1, 4 and 5))

\subsubsection{Material Properties}

\subsubsection{ATF FeCrAl}

Development of the $2^{\text {nd }}$ generation ATF FeCrAl alloys aims to obtain the optimized mechanical properties over a wide temperature range, without losing the promising oxidation resistance. The candidate base FeCrAl alloy composition, Fe-13Cr-4.5Al-0.05Y in weight percent, was down-selected from Phase I. Minor alloying additions, such as $\mathrm{Mo}, \mathrm{Nb}, \mathrm{Si}, \mathrm{Zr}$, and $\mathrm{C}$, are to be applied which target to control the desired microstructure suitable for improved properties, such as tensile strength, ductility, fabricability, oxidation resistance, thermal stability, and so on.

Microstructure and tensile properties from RT to $800^{\circ} \mathrm{C}$ will be evaluated as a function of alloy compositions and process conditions. Thermal stability of the microstructure and mechanical properties will also be assessed by using isothermal aging $\left(400-800^{\circ} \mathrm{C}\right)$. Several alloy compositions with the optimized properties will be down-selected and used for the commercial manufacturing study in the section 3.3.

Selected materials will be used for fabrication study via commercial vendor(s) in order to target the potential commercial tube fabrication.

Activities and Milestones

FY13

- Manufacture Generation I ATF FeCrAl 2013-2014 (COMPLETE)

- Test base material Generation I ATF FeCrAl 2013-2014 (COMPLETE)

- Manufacture Generation II ATF FeCrAl 2013-2016 (Section 3.1.1.1) (IN PROGRESS) 
FY 14

- Test base material Generation II ATF FeCrAl 2013-2016 (IN PROGRESS)

- M3FT-14LA0202162 (M3FT-15LA0202174) Complete tensile testing of Advanced FeCrAl Alloys and Issue Report 11/14/2014COMPLETE

- Continue manufacture and optimization of Generation II ATF FeCrAl (2013-2016) (Section 3.1.1.1) (IN PROGRESS)

FY15

- Continue optimization and testing of Generation II ATF FeCrAl (2014-2016)

- M3FT-15LA0202172 Complete and Report on Mechanical Testing and Characterization of Optimal FeCrAl Composition 5/29/2015

- M2FT-15OR0202291 Complete report on optimized properties of base metal and thin-walled tube of 2nd Gen ATF FeCrAl 8/14/2015

FY16

- Complete optimization of Generation II ATF FeCrAl before large scale tube production (20152016)

- M2 Final Report on Optimized Generation II ATF FeCrAl Alloy 4/20/2016

- Continue testing of Generation II ATF FeCrAl 2016-2022 (Sections 4 and 5)

\subsubsection{ATF ODS FeCrAl}

The 1st generation ATF ODS FeCrAl alloy is expected to provide superior mechanical strength from room to $900^{\circ} \mathrm{C}$ compared with wrought $\mathrm{FeCrAl}$ alloys. The tensile and creep properties of $\mathrm{Fe}-10-15 \mathrm{Cr}-5-$ $6 \mathrm{Al}+\mathrm{Y}_{2} \mathrm{O}_{3}\left(+\mathrm{Zr}\right.$, Ti, Hf) alloys will be characterized up to $800^{\circ} \mathrm{C}$. Steam oxidation testing (section 5.5.1) will be conducted in the $1200-1500^{\circ} \mathrm{C}$ range to ensure that mechanical properties optimization does no hurt the alloy oxidation performance. SEM and TEM observations will be carried out to assess the effect of processing parameters (ball milling duration, extrusion temperature...) and alloy composition on the alloy microstructure. Up to two alloy compositions will be down selected for hot rolling trials and tube fabrications.

Activities and Milestones

FY 14

- Manufacture Generation I ATF ODS FeCrAl (2013-2014) (COMPLETE)

- M2FT-14OR0202271 Complete report on production and properties of ORNL ATF (ODS) FeCrAl candidate alloys 09/02/2014 (COMPLETE)

- Test base material (oxidation, tensile and creep) Generation I ATF ODS FeCrAl (2013-2015) (and section 5.5.1)

FY 15

- Continue Testing of Generation I ATF ODS FeCrAl (2014-2015)

- M3FT-15OR0202281 Report on progress and properties of first generation ODS FeCrAl alloys for ATF cladding 9/18/2015

- Manufacturing of Generation II ATF ODS FeCrAl (2015-2016)

FY16

- Testing of base material properties (tensile, ductility, fracture toughness) of Generation II ATF ODS FeCrAl (and 5.5.1)

- Optimization of Generation II ATF ODS FeCrAl for thin tubing (2016-2017)

FY17 
- Testing of optimized Generation II ATF ODS FeCrAl (2017-2018) (and 5.5.1, 4 and 5))

\subsection{WELDING}

One of the most critical issues related to development of new improved accident tolerant cladding for an LWR is to develop a process for consistently producing sound, high quality welds to seal cladding tubes. One can develop the ideal material in to a flawless tube but still run into early failure because of a flawed weld. Aluminum containing alloys present two main difficulties toward producing high quality welds. First, the high aluminum content in these alloys makes it very difficult to weld using conventional Tungsten Inert Gas (TIG) welding techniques. Minor amounts of oxygen can easily react with aluminum to produce aluminum oxide stringers and porosity severely affecting the quality of the weld. Second, development of $\mathrm{FeCrAl}$ alloys as a weld overlay technology for fossil fuel applications has indicated that hydrogen ingress can lead to cracking and/or failure of the welds when specific compositions are to be welded. Thus, more advanced techniques such as laser welding and electron-beam welding in an inert atmosphere are preferred to produce a sound weld.

Initial trials using both these techniques have been successful. Thus, full weld characterization needs to be completed and a qualified weld process needs to be developed.

FeCrAl alloys with ODS strengthening can present another issue. These ODS FeCrAl alloys contain a fine uniform dispersion of oxide particles which improve the alloy high temperature strength and radiation tolerance. Thus, typical fusion welding techniques that melt the material during the process result in agglomeration of the oxide particles that degrades the alloy properties in the weld region. However, high quality ferritic ( $\mathrm{FeCr}$ and $\mathrm{FeCrAl}$ ) ODS joints have been produced using solid state welding techniques such as friction stir welding, inertial welding. Furthermore, innovative weld geometries or specific configurations such as thickening the tubes at weld joints could further enhance the weldability of wrought and ODS FeCrAl alloys limiting failure while in-service. Because the weld is at the end of the cladding tube, there may also be other methods of maintaining strength through increasing the thickness in that region.

\subsubsection{Weld development and properties}

Weld development will be required for both the ATF FeCrAl alloys and the ATF ODS FeCrAl alloys. Initial weld development can begin with coupons of the FeCrAl and FeCrAl ODS alloys but final testing will require thin walled tubes and end plugs of the dimensions desired for LWR cladding applications.

Initial weld development will center on down-selecting the techniques and optimizing the weld parameters. After weld parameters are optimized, samples will be provided for mechanical testing and characterization. Depending on the results of characterization and testing, further optimization of weld parameters may be required. Once a sound weld with optimal mechanical properties is obtained, a qualified weld process can be developed through testing the optimized parameters on advanced FeCrAl and $\mathrm{FeCrAl}$ ODS alloys in a range of tube dimensions required for LWR cladding applications.

As weld parameters are developed for Advanced FeCrAl and FeCrAl ODS alloys, mechanical testing and characterization of these welds will be required. This will include bend testing on the weld followed by surface inspection for cracking, tensile testing and characterization using optical microscopy, SEM and TEM where appropriate. This information will be provided for the weld development work package to aid in optimization of the weld parameters. 


\subsubsection{ATF FeCrAl}

Activities and Milestones

FY 14

- Initial weld development on Generation I ATF FeCrAl coupons (flat sheets) 2013

- Testing and analysis of Generation I ATF FeCrAl coupon welds (tensile and microstructure) 2013-2014

- Weld development of Generation I ATF FeCrAl tubes 2014

- Testing and analysis of Generation I ATF FeCrAl tubes (microstructure) 2014-2015

- M3FT-14IN0202102 Status Report on the Development of Weld Techniques for Thin Walled Tubing 12/30/2013 COMPLETE

- M3FT-14IN0202103 Summary report on ATF cladding alloy weld development 3/31/2014 COMPLETE

- Weld development on Generation II ATF FeCrAl coupons (also as part of weld qualification for ATF-1 rodlets) 2014

- Testing and analysis of Generation II ATF FeCrAl coupons (also as part of weld qualification for ATF-1 rodlets - tensile and bed test) 2014

- M3FT-14IN0202101 (M3FT-15IN0202072) Report on the Development of Weld Techniques for Thin Walled Tubing 3/31/2015 COMPLETE

FY 15

- Weld development on Generation II ATF FeCrAl tubes 2014-2015 (IN PROGRESS)

- M3FT-15IN0202071 Issue Status Report on Weld Development for FeCrAl Thin-Wall Cladding for LWR ATF 9/15/2015

FY 16

- Welding of commercial manufactured thin tubes (2015-2016)

- M2/3 Report on qualified weld process for ATF commercial FeCrAl thin walled tubing 5/1/2016

\subsubsection{ATF ODS FeCrAl}

There is confidence that welding of ATF ODS FeCrAl would not cause any major problems due to significant research conducted on welding of ODS alloys in nuclear and fusion energy research. Therefore, this will not be made as a primary priority.

When Generation II ATF ODS FeCrAl is optimized, welding qualification for thin tubes will be done to enable the insertion of thin tubes into test reactor(s).

Milestones and Activities

FY14

- Initial fabrication of ODS FeCrAl laser welds 2013-2014 (COMPLETE)

- M3FT-14OR0202273 (M3FT-15OR0202283) Complete initial evaluation of dispersion strengthened weld properties 10/17/14 (COMPLETE)

FY17

- Development of optimized Generation II ATF ODS FeCrAl thin tube welding (2017-18)

- Testing of optimized Generation II ATF ODS FeCrAl thin tube welds (2017-18) 


\subsection{TUBE FABRICATION}

Based on the results in the Section 3.1, selected ATF FeCrAl alloys which possess sufficient strength and oxidation resistance suitable for the accident tolerance fuel design, together with a good fabricability, will be used for tube fabrication study with support from commercial tube manufacturers. Seamed tube is not in the target of this program since it produces segregation of unexpectedly weaker (or sometime stronger) region along with the weld seam, even after proper heat treatment onto the tube, which is not ideal for the expected ATF design. The potential tube fabrication process of thin-wall, seamless tube product can be separated into two major parts; (1) preparation of parent ingots and machining the initial tube-form billets through piercing, and (2) making final, thin-wall tube product through extrusion, swaging, drawing, or pilgering, combined with heat treatments during or after the fabrication process. This task will focus of the latter part, which pursues the evaluation of the selected tube fabrication processes as well as the quality of processed tubes through the commercial tube manufacturers. Initial studies will attempt to produce tubing using swaging and annealing processes. Eventually it will be desirable to perform final tube processing using a tube pilger process and this provides tubing with a radial texture and can perform $30-40 \%$ reductions per pass. Limited tube manufacturing companies are available for tube pilger processing. Subcontracts will be placed with these companies to perform the pilger processing trials. The mechanical properties and microstructure of tubes developed through pilger processing will be compared to those successfully manufactured from swage and anneal and tube drawing processes (if successful).

\subsubsection{Laboratory scale tube manufacturing and testing}

\subsubsection{ATF FeCrAl}

Activities and Milestones

FY 14

- Manufacture laboratory scale tubes with Generation I ATF FeCrAl 2013-2014 (COMPLETE)

- M3FT-14LA0202152 (M3FT-15LA0202165) Report on Characterization of Thin-Walled Tubing of ATF Alloys 11/07/14 (COMPLETE)

- M3FT-14LA0202151 (M3FT-15LA0202164) Report on 1-3 ft. long FeCrAl Tube Production 04/30/2015 (IN PROGRESS)

FY 15

- Manufacture laboratory scale tubes with Generation II ATF FeCrAl 2014-2015

- M3FT-15LA0202162 Produce and Report on 5-10 foot long tubing from Optimal Phase II FeCrAl alloy 7/17/2015

- M2FT-15LA0202161 Submit final report on viability of thin wall tube forming of ATF FeCrA1 $9 / 15 / 2015$

- Perform property test on Generation II ATF FeCrAl 2014-2015

- M3FT-15LA0202202 Report on Results from Qualification Testing of FeCrAl Tubing 9/11/2015

- Manufacture laboratory scale tubes with optimized Generation II ATF FeCrAl 2015

- M2FT-15OR0202291 Complete report on optimized properties of base metal and thin-walled tube of 2nd Gen ATF FeCrAl 8/14/2015

\subsubsection{ATF ODS FeCrAl}

Tube fabrication process includes warm-/hot-drawing to obtain thin wall, seamless tube form, but most of the ODS alloys exhibit poor deformability at low temperature range due to their high-strength natures. 
This subtask will therefore focus on the evaluation of deformability of the selected ATF ODS FeCrAl alloys to target potential tube fabrication process. The microstructure together with the processing conditions would need to be carefully controlled, such as grain size, process temperature, thickness reduction rate, intermediate heat treatments, etc., in order to make the tube fabrication of the ODS FeCrAl alloys possible. Various combinations of processing routes at temperature ranging from room (drawing, pilgering, etc.) to $1150^{\circ} \mathrm{C}$ (extrusion, annealing, etc.) will be assessed to find the optimized process conditions.

Research have been done on commercially available ODS material MA956. It is expected that optimized Generation II ATF ODS FeCrAl will have much improved ductility than MA956 ensuring easier tube fabrication.

The MA956 is only useful as a surrogate for an ATF FeCrAl ODS variant.

Activities and Milestones

FY 14

- M3FT-14PN0202411 (M3FT-15PN0202374) Produce initial MA956 thin-walled tubing 10/27/2014 COMPLETE

- M3FT-14PN0202412 Establish advanced fabrication process for MA956 tubing 6/30/2014 (incorporated in M3FT-15PN0202371)

- M3FT-14PN0202413 Demonstrate advanced fabrication process for MA956 Tubing 12/31/2014 (incorporated in M3FT-15PN0202371)

FY 15

- M3FT-15PN0202371 Produce thin walled tubing of an advanced ODS ferritic steel (MA956) using pilger processing $5 / 30 / 2015$

- M3FT-15PN0202373 MA-956 Tubing Process Development Report 9/30/2015

FY $16 / 17$

- Production thin plates of Generation II ATF ODS FeCrAl to demonstrate manufacturability of thin tubes $(2016-2017)$

FY17/18

- Production of thin plates of optimized Generation II ATF ODS FeCrAl to demonstrate manufacturability of thin tubes (2017-2018)

- Testing of thin plates of optimized Generation II ATF ODS FeCrAl to demonstrate (2017-2018)

\subsubsection{Commercial tube fabrication and testing}

Trial tube fabrication of selected ATF FeCrAl alloys through commercial manufactures will be pursued. The materials will be down-selected from the model ATF FeCrAl alloys (Phase I), and the Generation II ATF FeCrAl alloys (Phase II). Selected ATF ODS FeCrAl alloys may also be evaluated if the process optimization in subtask 3.1.1.2 and 3.1.2.2 was successful.

ATF FeCrAl and ATF ODS FeCrAl materials will be respectively cast or ball milled by a commercial vendor, extruded at ORNL to make either bar shape or tube shape as initial billets, machined into a tube shape within the required specification of the following process, and then swaged or cold-/warm/-hotdrawn at commercial tube manufacturers to make seamless tube forms with less than $500 \mu \mathrm{m}$ wall thickness and $\sim 10 \mathrm{~mm}$ outer diameter. Century tubing, 7910 Dunbrook road, San Diego, CA 92126-4371 and Rhenium Alloys, Inc., North Ridgeville, $\mathrm{OH}$, are to be selected as commercial tube manufacturers who have experiences and capabilities to draw thin wall tubes of metal-base materials. 


\subsubsection{ATF FeCrAl}

Tube manufacturing process includes intermediate annealing in the course of drawing in order to soften the work hardened materials and to allow further thickness reduction. This intermediate annealing process will also affect the microstructure evolution and, therefore, the mechanical properties of final product, which needs to be carefully controlled. Drawn tubes at the commercial manufacturers will be inspected in terms of surface-finish condition, size tolerance, microstructure, and mechanical properties, which will be evaluated as a function of process conditions. Pilgering process will also be attempted to apply continuous swage-like cold work onto the tubes, which can also be utilized for controlling final tube geometry. For this processing, subcontracts will be placed with Sandvik Special Metals, 235407 E. SR397, Kennewick, Washington, 99337

Potential commercialization processes of tube fabrication include casting, forging/rolling, piercing, extrusion, swaging, drawing, pilgering, and heat treatments. This subtask mainly focuses on the soundness of the cast ingots prepared by commercial vendors. Commercial product would require relatively large size (orders of 10-1,000 lbs.) ingots as the initial billets. The quality of such ingots, in terms of chemical specification, compositional uniformity of the whole ingot, minimized solidification defects, etc., will be critical for downstream processing as well as the final products. The ingot size, however, would be usually too large to evaluate all of such characteristics. Therefore, the soundness of the cast ingots will be assessed after applying extrusion process, which reasonably makes the sample size small and easy to characterize as well as to compare with the lab heats.

Sophisticated Alloys, Inc., Butler, PA, is to be selected as a commercial cast ingot vendor who can provide a vacuum induction melt (VIM) ingot up to $500 \mathrm{lb}$. Evaluation of the materials includes chemical analysis, microstructure characterization after processing, and tensile testing from RT to $800^{\circ} \mathrm{C}$.

Evaluation of quality and properties of Generation II ATF FeCrAl alloy tubes produced by commercial manufacturers will be pursued. The results obtained in the subtask 3.1.1 will be used for optimization of tube fabrication process of the selected Generation II ATF FeCrAl alloy tube(s). The quality evaluation includes microstructure, tensile properties, oxidation resistance, creep resistance, and burst testing. At least $300 \mathrm{~mm}$ length tubes will be fabricated with uniform, optimized microstructure, and the properties will be evaluated under several different work packages. Part of the tube materials will also be provided for the weld study in the section 3.2.

Activities and Milestones

FY15

- Development and optimize 1 tube production for of Generation II ATF FeCrAl 2015 (IN PROGRESS)

- M2FT-15OR0202252 Determine viability of commercial heat production of ATF FeCrAl and issue summary report 9/4/2015 (IN PROGRESS)

FY16

- Report on the Properties of Generation II ATF FeCrAl Alloy Tubes Fabricated by Commercial Manufacturer 06/30/2016

\subsubsection{ATF ODS FeCrAl}

Fabrication of ODS FeCrAl tubes will require the production of large quantities of ODS powder. Collaboration will be initiated with MBN nanomaterialia and/or other powder manufacturers to fabricate sufficient quantities of ODS powder. Careful control of the powder chemistry and impurity levels will be conducted to ensure good oxidation resistance. The powder will be extruded at ORNL to make bar shape 
and characterize the microstructure, mechanical properties, and oxidation performance of the alloys. If the ODS alloy fabricability at temperature below $300^{\circ} \mathrm{C}$ is close to the fabricability of ATF FeCrAl, the ODS tube fabrication process will be based on the fabrication process for ATF FeCrAl tubes. If hot drawing $\left(>300^{\circ} \mathrm{C}\right)$ needs to be used, collaboration with tube manufacturers will be initiated to develop high temperature drawing dies.

Activities and Milestones

FY16

- Manufacturing of commercial Generation II ATF ODS FeCrAl powder (2015-2016)

FY17

- Characterization of commercial Generation II ATF ODS FeCrAl powder (2016-2017)

FY18

- Manufacturing of optimized Generation II ATF ODS FeCrAl thin tubes (2017-2018)

FY19

- Testing and reporting on optimized Generation II ATF ODS FeCrAl thin tubes properties (20182019)

\subsection{QUALITY ASSURANCE OF MATERIAL FABRICATION}

ORNL's QA approach for the gamut of technical pursuits comprising the work scope for the irradiation FeCrAl Clad is described in Document \#QAP-ORNL-FCT-01 entitled Quality Assurance Plan and Interface Document for Fuel Cycle Technology Research and Development Activities Conducted at Oak Ridge National Laboratory (hereafter referred to as the QAP). The QAP is established, maintained, and executed in accordance with the applicable criteria of the ORNL Quality Assurance Program Description, and is an enabling document for quality-related work associated with FCT activities to be conducted at ORNL or for ORNL by any subcontracted organizations. The ORNL QA program addresses the requirements contained in DOE Order 414.1D and in 10CFR830, Subpart A and is applied on a graded basis to all work activities at the site. ORNL's QA program also provides the flexibility and authorization to develop activity-specific programs to meet national and international quality standards and sponsor needs.

ORNL management recognizes that - though FCT activities are conducted as part of an ongoing R\&D effort - successful outcomes represent potential inputs to future design and licensing decisions. The work scope described herein also requires interface with the ATR, a DOE nuclear facility and other materials test reactor operators. Therefore, activities shall be conducted under the QA rigor specified in both the ASME NQA-1-2008 with the NQA-1a-2009 Addendum (Quality Assurance Requirements for Nuclear Facility Applications, hereafter referred to as NQA-1-2008) standard and in the NRC-mandated 10CFR50 Appendix B (Quality Assurance Criteria for Nuclear Power Plants and Fuel Reprocessing Plants). ORNL management's intent is to ensure that this targeted quality program is satisfactory in addressing all FCRD work package milestones assigned to ORNL including those designated Quality Rigor Level 1as described in the FCT's Quality Assurance Program Document (current version - Revision 2 effective December 20, 2012).

The requirements of the cited quality standards are imposed on a graded basis using the guidance contained in NQA-1-2008, Part IV, Subpart 4.2 (Guidance on Graded Application of Quality Assurance for Nuclear-Related Research and Development). Further, this plan is intended to meld the requirements contained in the previously cited national standards with those described in the FCT-issued Quality Assurance Program Document (QAPD). The FCT QAPD represents the highest-tier QA document specific to the FCT mission and applicable to the various work scopes, activities, and tasks funded at DOE-sponsored entities including ORNL. 
For FCT activities conducted at ORNL, QA requirements are implemented by line and program management through a combination of the ORNL FCT QAP, associated subordinate QA procedures, and the mandates and requirements conveyed through the ORNL Standards Based Management System (SBMS). The SBMS is ORNL's web-based system for the translation and implementation of applicable laws, orders, and regulatory requirements through the deployment of Laboratory-wide subject areas and procedures. The QAP is intended, in part, to provide the framework for establishing and maintaining a QA program to fulfill the applicable requirements described in the NQA-1-2008 standard and in 10CFR50 Appendix B as they apply to FCT activities. The QAP - plus any additional referenced QA implementing procedures and SBMS documents necessary for conduct of the described work activities constitute the ORNL FCT QA manual. 


\section{NORMAL OPERATION ENVIRONMENTAL EFFECTS}

This section aims to define the work scope for assessing the behavior of FeCrAl cladding under normal operating conditions in LWR fuel assemblies. Normal operating conditions imply cladding average temperature of $300-400^{\circ} \mathrm{C}$ where the metal is in contact with the primary coolant on the outside for the duration of roughly five years. The environmental effects arise from neutron irradiation, hydrothermal corrosion, fuel-cladding chemical and mechanical interactions, and loading on the fuel assembly structure. Therefore, the work scope requires that unirradiated material properties be characterized and understood in detail. After this step, the separate effects from the environment should be examined. Ultimately, and integral fuel tests with the combination of all these environmental effects will be necessary to fully assess the in-pile behavior of the cladding.

\subsection{NON-IRRADIATED MATERIAL PROPERTIES}

\subsubsection{Base material properties}

Properties that will be covered under section 3.1.2 are:

1. Tensile properties from room temperature to $800^{\circ} \mathrm{C}$

2. Microstructural characterization and analysis

3. Fracture toughness (ODS FeCrAl)

4. Melting temperature

Properties that are not coved in section 3.1.2 and are required by modelers are listed below with explanation of what will be assumed for these properties until they are measured or calculated.

1. Physical properties

a. Density - Assume that of stainless steel. This will only be affected by the chemical composition of the material, which should be finalized with optimized Generation II ATF FeCrAl and ODS ATF FeCrAl.

b. Surface roughness - use estimate until thin tube development is complete

c. Emissivity - use stainless steel properties until thin tube development is complete

2. Chemical composition - use Generation I until Generation II is optimized

3. Thermal properties

a. Thermal Conductivity (temperature and dose dependent) - use stainless steel properties until thin tube development is complete

b. Heat Capacity - use stainless steel properties until thin tube development is complete

c. Specific Heat - use stainless steel properties until thin tube development is complete

d. Thermal Expansion - use stainless steel properties until thin tube development is complete

4. Mechanical properties

a. Elastic Modulus

b. Shear Modulus

c. Hardening effects

d. Creep (temperature and dose dependent)

e. Yield stress/strain - obtain from tensile properties

5. Microstructure

a. Swelling and or growth models - use data for simple ferritic Fe-Cr data (see that of Katoh et al. [4] and Little and Stow [5]) 
6. Coolant chemistry

a. Water-side corrosion (temperature and dose dependent)

b. Internal oxidation

c. Crud deposition

d. Hydrogen pic-up

\subsubsection{Fuel Clad Chemical interaction (FCCI)}

Since basic thermodynamic models can provide a clear picture of fuel-cladding chemical interaction in the unirradiated state, it is concluded that experiments in this area are redundant. This is particularly the case since during irradiation the combined effect of non-equilibrium state, presence of abundant fission products, and the large change in oxygen activity in the urania pellets will present conditions much different than what can be created in the laboratory tests on unirradiated fuel and cladding specimens. Therefore, the focus should be on in-pile testing and PIE to capture FCCI effects, if any 4.2.2.

\subsection{IRRADIATION EFFECT ON MATERIAL PROPERTIES}

Under irradiation, the desirable microstructural properties developed using the techniques in the alloy development phase may be severely altered. As a result, the macroscopic response of the material may be altered as well, including changes in the yield strength, ductility, fracture toughness, and resistance to corrosion, among others. Work on ferritic $\mathrm{Fe}-\mathrm{Cr}$ based alloys has shown several important irradiation induced effects for Fe-based ferritic alloys that can alter the structural, physical, and chemical properties of the alloys. These include dislocation loop formation and evolution, void swelling, precipitation and radiation induced segregation. A brief summary of the expected radiation effects, which will show significant changes on the macroscopic response of $\mathrm{FeCrAl}$ alloys, is provided below.

Dislocation loop formation and evolution: Based on experience from research and development conducted on reduced activation ferritic/martensitic (RAFM) steels, low temperature hardening and embrittlement could occur in FeCrAl alloys when irradiated below one-third of the melting point of the alloy $\left(<400-500^{\circ} \mathrm{C}\right)$. Below these temperatures, interstitials created from the damage cascade and quench tend to be more mobile compared to vacancies. These mobile interstitials can migrate and form extended length defects including dislocation loops. It is generally accepted $a / 2\langle 111\rangle$ and $a\langle 100\rangle$ dislocation loops are formed in neutron irradiated ferritic Fe-Cr based alloys. The ratio of $a / 2\langle 111\rangle$ and $a\langle 100\rangle$ loops have been reported to be highly dependent on irradiation dose and temperature. This is partially contributed to the fact that in a BCC matrix the $a / 2\langle 111\rangle$ loops are glissile (mobile) while $a\langle 100\rangle$ loops are sessile (immobile) at temperatures relevant to cladding applications. The mobility of the loops could also have significant impacts on the hardening observed in FeCrAls. Dislocation loop formation can impact other radiation effects as they have the potential to act as major sinks for irradiation induced point defects. Clearly, the quantification of the density and size of the different loop types must be understood to develop a fundamental understanding of the impact of radiation on the structural, physical, and chemical proprieties of the FeCrAl alloys irradiated under prototypical LWR conditions.

Void swelling: Void swelling is a concern as the formation of voids can lead to a density decreases in the clad and dimensional changes under irradiation. Furthermore, production of small helium filled bubbles on grain boundaries could embrittle the grain boundaries and lead to the significant embrittlement of the FeCrAl alloy. Void swelling occurs as a result of vacancies produced via the damage cascade and quench migrating to form vacancy clusters which are inturn stabilized by innate gases or helium produced by $(n, \alpha)$ reactions. In general, Fe-Cr based alloys with BCC structure have shown excellent resistance to radiation-induced void swelling due to effect of solutes on the vacancy mobility and vacancy loss to the overall microstructure (such 
as dislocation loops and precipitates). Finally, at the irradiation temperatures expected for $\mathrm{FeCrAl}$ cladding, the significant recombination is expected which should limit the formation of voids. Given this, the quantification of the void swelling resistance must be understood and verified.

Phase Stability: Past experience has shown phase instability to be a significant contributor to radiation hardening and significant shifts in the ductile to brittle transition temperature (DBTT) in $\mathrm{Fe}-\mathrm{Cr}$ based ferritic alloys. Of particular interest for simple $\mathrm{FeCrAl}$ alloys is the precipitation of Cr-rich $\alpha^{\prime}$. Cr-rich $\alpha^{\prime}$ has been observed in $\mathrm{Fe}-\mathrm{Cr}$ based ferritic alloys via both thermal aging and neutron irradiation with irradiation accelerating the formation of $\alpha^{\prime}$ due to the radiation-induced defects enhancing the $\mathrm{Cr}$ redistribution. The formation of $\alpha^{\prime}$ has been observed to be both compositionally and temperature dependent with higher temperatures promoting larger $\alpha^{\prime}$ precipitates with reduced density while high $\mathrm{Cr}$ contents leading to a high density of $\alpha^{\prime}$ precipitates in the matrix. The $\alpha^{\prime}$ phase is a $\mathrm{BCC}$ phase containing $\sim 80 \mathrm{wt} . \% \mathrm{Cr}$ and a barrier to dislocation motion under loading leading to hardening and embrittlement. Furthermore, the formation of $\mathrm{Cr}$-rich precipitates will diminish the bulk $\mathrm{Cr}$ concentration and could impact the corrosion resistance under normal operating conditions. Shifts in the DBTT temperature of several $\mathrm{Fe}-\mathrm{Cr}$ alloys have been shown to be significantly impacted by the size and number density. Most of the experience on $\alpha^{\prime}$ formation under irradiation is based on $\mathrm{Fe}-\mathrm{Cr}$ alloys on the $\alpha$ formation and embrittlement of $\mathrm{FeCrAl}$ alloys remains weakly explored and must be investigated and understood to aid in the development of a FeCrAl alloy for cladding applications.

Radiation Induced Segregation: Radiation induced segregation (RIS) is a microchemical change at defect sinks (grain boundaries, free surfaces, etc.) due to preferential solute-defect coupling and migration under irradiation. In FCC steels, RIS leads to depletion of $\mathrm{Cr}$ at the grain boundary leading to intergranular corrosion during operation and hypothesized to be a leading contributor to irradiation assisted stress corrosion cracking (IASCC) in core internals. For BCC Fe-Cr alloys, the response is quite complex with $\mathrm{Cr}$ enriching, depleting, or not segregating to grain boundaries under irradiation depending on alloy, dose, dose rate, and grain boundary type. No experimental evidence on RIS or trends have been determined for FeCrAl alloys. Enrichment of Cr could lead to microstructural instability and precipitation at the grain boundaries. In concert with $\alpha^{\prime}$ formation, RIS could deplete $\mathrm{Cr}$ intra-granularly leading to decreased corrosion resistance. Enrichment of $\mathrm{Al}$ could severally embrittle grain boundaries and promote intergranular cracking under irradiation. The influence of RIS at off-normal operating conditions remains weakly explored as well. Due to the lack of knowledge in FeCrAl alloys, and limiting systematic studies conducted in $\mathrm{BCC} \mathrm{Fe}-\mathrm{Cr}$ systems, no predictions can be made on the RIS response and resulting macroscopic changes in FeCrAl alloys. Thus, a preliminary investigation into RIS in FeCrAl alloys is needed to assess the implications of RIS for FeCrAl cladding.

Nano-cluster stability (NFA-ODS FeCrAl only): Nano-featured alloys using oxide dispersion strengthening (NFA-ODS) alloys present a unique radiation effect as the small oxide nanoclusters could become unstable under irradiation. The stability of nano-clusters is a balance between ballistic dissolution and back diffusion annealing of ejected oxide atoms. At low temperatures $\left(<400{ }^{\circ} \mathrm{C}\right)$, there could be loss of sufficient back diffusion leading to dissolution of nano-clusters if the dose rate is relatively high. Loss of the nano-cluster distributions due to irradiation would significantly impact other radiation responses as the defect sink density would drop several orders of magnitude. Loss of defect sinks would promote dislocation loop formation, void and He bubble formation and radiation induced segregation in NFA-ODS FeCrAl alloys.

Furthermore, such effects could impact the creep resistance of the material. Clearly, an understanding on the stability and response of nano-clusters in NFA-ODS FeCrAl alloys must be understood. 
The discussed radiation effects will contribute to the macroscopic (secondary) response of FeCrAl alloys under normal LWR operating conditions. Secondary responses of interest include radiation hardening and embrittlement, fuel cladding chemical interactions (FCCI), radiation enhanced and induced creep and decreases in fatigue life. Hardening will increase strength of the material at the expense of ductility. Significant hardening can cause embrittlement of the material. FCCI could be major performance-limiting phenomena of $\mathrm{FeCrAl}$ cladding. Interactions between the fuel and $\mathrm{FeCrAl}$ clad could consume the cladding leading to weakening of the inner wall of the cladding. Weakening of the clad wall could lead to failure due to internal mechanical stresses from the swelling fuel or from internal pressurization during fission gas release. Cladding could fail due to creep rupture after prolonged high temperature exposure and radiation. The formation of dislocation loops and loss of oxide nano-clusters in the NFA-ODS $\mathrm{FeCrAl}$ could detrimentally impact the creep-rupture strength of the cladding leading to failure well below the formal yield stress of FeCrAl alloys. Secondary effects could be exacerbated in modified areas such as in the weld regions near the top and bottom caps of the fuel rod assembly. Fusion welding can alter the local microstructure and microchemistry and thus alter the primary and secondary radiation responses of the fuel assembly. All of these effects (primary and secondary) must be well characterized and understood for all portions of a fuel assembly to ensure successful operation of FeCrAl clad in LWR environments.

Properties depended on temperature and irradiations to consider as input to reactor modeling are:

1. Thermal properties

a. Thermal Conductivity (temperature and dose dependent)

2. Mechanical properties

a. Hardening effects

b. Yield stress/strain - obtain from tensile properties

c. Creep (temperature, dose rate, and dose dependent)

3. Microstructure

a. Swelling and or growth models

4. Coolant chemistry

a. Water-side corrosion (temperature and dose dependent)

b. Internal oxidation

c. Crud deposition

d. Hydrogen pic-up

\subsubsection{Irradiation effect on baseline properties}

The following section are describes the methods to understand the fundamental mechanisms controlling the primary radiation response (dislocation loops, void swelling, precipitation, and RIS) with follow on studies to understand how these primary responses effect the secondary macroscopic responses. Empirical observations will be utilized to aid in the development of mitigation strategies for the formation of radiation-induced defects and assist with the development of a finalized, radiation tolerant FeCrAl alloy for fuel-cladding applications. In this design, a holistic view of the performance of FeCrAl alloys under neutron irradiation can be developed. Furthermore, the science-based investigation will provide knowledge on the 'tunable knobs' such as grain size, alloy composition, and processing routes which can be tuned to customize the radiation tolerance and ultimately the performance of $\mathrm{FeCrAl}$ alloys for nuclear applications.

Firstly the radiation response of $\mathrm{FeCrAl}$ alloys as a function of alloy main composition $\mathrm{Fe}, \mathrm{Cr}$ and $\mathrm{Al}$ will be determined by irradiation of Generation I ATF FeCrAl materials. Bonney et al. [2] have reviewed the literature on $\mathrm{Cr}$ bearing $\mathrm{Fe}$ based alloys and showed the $\alpha^{\prime}$ formation under irradiation is a function of 
both temperature and $\mathrm{Cr}$ content while the size and number density of $\alpha^{\prime}$ has been shown to strongly influence the DBTT of Fe-based alloys, although limited data exists on the contributions of Al to the formation of $\alpha^{\prime}$. The data generated including strength and ductility data as well as $\alpha^{\prime}$, void swelling, dislocation loop formation, and RIS will provide an initial 'first look' on the radiation tolerance of Generation I ATF FeCrAl alloys and assist with the determination of the compositional operating range suitable for $\mathrm{FeCrAl}$ alloys under prototypical LWR neutron radiation environments.

The irradiation results of Generation I ATF FeCrAl and ODS FeCrAl will provide baseline understanding for radiation tolerance of $\mathrm{FeCrAl}$ alloys on model $\mathrm{FeCrAl}$ systems. As the alloy development task tunes the compositions closer to finalized compositions with additions of alloying elementals for solid solution strengthening, grain refinement, and increases corrosion/oxidation resistance these alloy additions and microstructural changes could also impact the radiation tolerance of the FeCrAl clad. Radiation effects are quite complex, are often interrelated, and often directly correlated with the starting state of the test specimen.

The Generation I ATF FeCrAl and ODS FeCrAl irradiation results will be utilized in the development of Generation II ATF FeCrAl and ODS FeCrAl. The down selection process will reduce the number of alloys to be investigated therefore freeing up opportunities for investigations into weldments developed under the welding development task and provide detailed investigations on trends including the dose and temperature response of the second generation $\mathrm{FeCrAl}$ clad as well as conduct more sophisticated secondary effects studies such as water-side corrosion and $\mathrm{UO}_{2}-\mathrm{FeCrAl}$ compatibility studies.

Knowledge (techniques, known trends, etc.) gained on earlier generations will be applied to focus efforts on establishing a database on the radiation tolerance of optimized Generation II ATF FeCrAl and ODS FeCrAl alloys. Empirical evidence will be combined with targeted modeling to extrapolate towards transient and off-normal conditions. Miniaturized fuel assemblies will be investigated and correlated with the database and modeling efforts to confirm the expected radiation tolerance of the finalized $\mathrm{FeCrAl}$ alloy.

Properties that will be measured on HFIR irradiated materials are:

1. Microstructure (for low dose specimens)

2. Microchemical redistribution

3. Uniaxial tensile strength (yield strength, ultimate tensile strength, total elongation, uniform elongation)

4. Fracture toughness

Irradiation of miniaturized rodlets and diffusion couple rigs as part of the ATR ATF-1 (4.2.2) irradiation campaign and instrumented irradiated creep rigs within the Halden Reactor (4.2.3) can be used to verify or supplement these properties.

Activities and Milestones

FY13

- Irradiate Generation I ATF FeCrAl materials in HFIR (2013-2015) (COMPLETE)

FY14

- Conduct post irradiation examination on Generation I ATF FeCrAl (2014 -2016) (IN PROGRESS)

- M3FT-14OR0202222 "Submit report on stability of model ATF alloys regarding Cr levels (9/30/2014) (COMPLETE)

FY15 
- M2FT-15OR020224 "Summary report on the effect of composition on the irradiation embrittlement of generation1 ATF FeCrAl (9/18/2015)

- Prepare rabbit capsules for Generation II ATF FeCrAl (including weldments) materials for HFIR irradiation (2014-2015) (IN PROGRESS)

- Prepare rabbit capsules for Generation I ATF ODS FeCrAl materials for HFIR irradiation (20142015) (IN PROGRESS)

- M3FT-15OR0202241 "Report on ATF FeCrAl Fracture Toughness Rabbits Series completion" $(06 / 26 / 2015)$

FY16

- Post irradiation examination of Generation II ATF FeCrAl (2016 - 2017)

- Post irradiation examination of Generation I ATF ODS FeCrAl (2016 - 2017)

- M2 "Report on the development of a consolidated irradiated FeCrAl materials database based on PIE activities of Gen I, Gen II, and commercial alloys test reactor irradiation campaigns." (9/30/2016).

- Prepare rabbit capsules for Generation II ATF ODS FeCrAl materials for HFIR irradiation (20162017)

FY17/18

- Map radiation temperature and dose effects (phase stability, void swelling, etc.) from $200-550^{\circ} \mathrm{C}$ FY18/19 and 0-20 dpa of optimized Generation II ATF FeCrAl thin tubes (2017-2018)

- Post irradiation examination of optimized Generation II ATF FeCrAl thin tube irradiation (20182019)

- Map radiation temperature and dose effects (phase stability, void swelling, etc.) from $270-450^{\circ} \mathrm{C}$ and 0-EOL dose of optimized Generation II ATF ODS FeCrAl thin tubes (2018-2019) FY19/20

- Post irradiation examination of optimized Generation II ATF ODS FeCrAl thin tube irradiation (2019-2020)

\subsubsection{Fuel clad interaction}

\subsubsection{Fuel Clad Chemical Interaction (FCCI)}

The microstructural and mechanical characterization of FeCrAl cladding materials conducted in 4.2.1 will provide a fundamental understanding of the radiation tolerance of the candidate clads but are far from fully characterizing the response of thin-walled clad during service where other variables such as those introduced from the fuel could alter the operating conditions. Therefore, other targeted experiments are needed inline with those proposed in 4.2.1 to understand the controlling performance factors for FeCrAl clad within the proposed fuel-clad system. FeCrAl clad will experience a bi-axial stress state due to internal loading from fission-gas release and fuel swelling (Note Section 4.2.1 only examines uniaxial tensile states for screening). As discussed previously, fuel chemical cladding interaction (FCCI) could weaken the cladding leading to failure at lower stresses than anticipated by simple uniaxial tensile tests. Therefore, the ATF-1 (small I-position in ATR) campaign will investigate any FCCI between the $\mathrm{UO}_{2^{-}}$ FeCrAl fuel-clad system utilizing simplified and miniaturize fuel rodlets.

lower stresses than anticipated by simple uniaxial tensile tests. Therefore, the ATF-1 (small I-position in ATR) campaign will investigate any FCCI between the $\mathrm{UO}_{2}-\mathrm{FeCrAl}$ fuel-clad system utilizing simplified and miniaturize fuel rodlets.

ODS FeCrAl chemical interaction with fuel is expected to very similar with that of ATR FeCrAl clad, and therefore are not investigated separately. 
Additional information will be gathered from Integral Fuel Test (section 4.6). In particular the integral fuel testing will ensure cladding creep-down onto the fuel pellet (given the pressure differential from the coolant to the rod internals). In this manner, any FCCI is facilitated and can be assessed during the PIE.

Activities and Milestones

FY14

- Design and build ATF-1 rodlet using Generation II ATF FeCrAl and UO2 (2013-2014) (COMPLETE)

- M3FT-14OR0202251 Development and delivery of ORNL's candidate FeCrAl-UO2 system test capsules and accompanying data package for ATF-1 irradiation campaign 09/19/2014 (COMPLETE)

- Irradiation of $\mathrm{FeCrA1} / \mathrm{UO} 2$ rodlet into ATR (2014-2020 - dependent on ATR schedule) (IN PROGRESS)

FY15

- Complete rodlet assembly for material contact experiment with Generation II ATF FeCrAl and UO2 for ATF-1 experiment (2014-2015)

- M2FT-15OR0202271-Complete Report and QA package for the second (material contact) FeCrAl ATF-1 capsule (09/30/2015)

- Completion of low burn-up irradiation of FeCrAl-UO2 rodlet (10 GWd/Mt burn-up) (2014-2015) (IN PROGRESS)

FY16

- Irradiation of material contact experiment with Generation II ATF FeCrAl and UO2 (2015-2020 - dependent on ATR schedule)

- Complete PIE of low burn-up ATF-1 rodlet designs (2016-2018)

- Complete low burn-up (10 GWd/Mt burn-up) irradiation of material contact experiment with Generation II ATF FeCrAl and UO2 (2015-2016)

FY17

- Complete low burn-up (10 GWd/Mt burn-up) PIE of material contact experiment with Generation II ATF FeCrAl and UO2 (2017-2019)

FY18

- Completion of medium burn-up irradiation of FeCrAl-UO2 rodlet (30 GWd/Mt) (2014-2018)

- Complete PIE of medium burn-up ATF-1 rodlet designs (2018-2020)

FY19

- Complete medium burn-up (30 GWd/Mt burn-up) irradiation of material contact experiment with Generation II ATF FeCrAl and UO2 (2015-2019)

FY20

- Complete medium burn-up (30 GWd/Mt burn-up) PIE of material contact experiment with Generation II ATF FeCrAl and UO2 (2020-2022)

- Completion of high burn-up irradiation of FeCrAl-UO2 rodlet (50 GWd/Mt) (2014-2020) FY21

- Complete PIE of high burn-up ATF-1 rodlet designs (2021-2023)

\subsubsection{Irradiation Assisted Creep}

The first activity pertains to in-pile creep testing of ATF FeCrAl alloys, aiming to provide reliable in-pile data on creep compliance coefficient of these materials as a function of dose and temperature. Such data is necessary input to fuel performance modeling activities and will be supportive of the qualification data package for the eventual application of $\mathrm{FeCrAl}$ as an LTR in a commercial LWR. A limited temperature region $\left(\sim 350^{\circ} \mathrm{C}\right)$ shall be probed that is directly applicable to the temperature of LWR fuel cladding 
under normal operating conditions. The creep tests take advantage of in-pile instrumentation and control systems native to the Halden facility to collect accurate in-pile data with reliable environmental controls. Detailed description of these test rigs is provided elsewhere [2], but briefly they utilize adjustable mixture gas flow in annular regions couple with multiple thermocouples in each capsule for precise temperature control. The stress on the creep specimens is controlled by direct gas pressure control inside a bellows attached to the creep specimen. The creep strain is also directly measured using a calibrated LVDT attached to the end of the specimen. Three FeCrAl specimens are being tested with the test conditions detailed in Table I. The in-pile creep data is meant to quantify the creep strain rate for these materials under normal operating conditions. This information is essential input to fuel performance analysis tools to understand and assess integral fuel rod behavior for these ATF materials concepts upon deployment.

Table 1 Temperature and stress conditions for the FeCrAl creep specimens.

\begin{tabular}{|l|l|c|c|c|c|c|c|c|}
\cline { 2 - 9 } \multicolumn{1}{c|}{} & Cumulative months & 2 & 4 & 6 & 8 & 10 & 12 & 14 \\
\cline { 2 - 10 } \multicolumn{1}{c|}{} & Period \# & 1 & 2 & 3 & 4 & 5 & 6 & 7 \\
\hline Specimen & Temperature $\left[{ }^{\circ} \mathrm{C}\right]$ & \multicolumn{7}{c|}{ Stress [MPa] } \\
\hline FeCrAl-1 & 350 & 325 & 300 & 250 & 200 & 100 & 350 & 325 \\
\hline FeCrAl-2 & 350 & 325 & 300 & 250 & 200 & 100 & 350 & 325 \\
\hline FeCrAl-2 & 350 & 0 & 0 & 0 & 0 & 0 & 0 & 0 \\
\hline
\end{tabular}

FeCrAl-1 composition is Fe-13Cr-5Al-2Mo-0.2Si-1Nb-0.15Y in wt.\%.

FeCrAl-2 composition is Fe-13Cr-5Al-2Mo-0.2Si-0.15Y in wt.\%.

Activities and Milestones:

FY-14

- Design of in-pile creep irradiation experiment for Generation II ATF FeCrAl tensile coupons (2013-2014) (COMPLETE)

FY-15

- Irradiation of in-pile creep irradiation experiment for Generation II ATF FeCrAl tensile coupons (2014-2016) (IN PROGRESS)

- M2FT-15OR0202351 Report on design and preliminary data of Halden in-pile creep rig $9 / 11 / 2015$

FY16

- Write report on completion of in-pile creep irradiation experiment for Generation II ATF FeCrAl tensile coupons (2016)

FY17/18

- Post irradiation of in-pile creep irradiation experiment for Generation II ATF FeCrAl tensile coupons (2017-2018)

- Design of short tubes (optimized Generation II FeCrAl commercial tubes) creep test in Halden reactor cooling water (2016-2017)

- Irradiation test of short tubes (optimized Generation II FeCrAl commercial tubes) creep test in Halden reactor (2017-2018)

\subsection{AQUEOUS CORROSION}

The fuel cladding is exposed to the PWR/BWR water environment during its operation and compatibility with this environment is a primary concern. Compatibility implies a low reaction (oxidation) rate with the water and its constituents (oxygen, etc.) and the stability of the reaction product to limit dissolution into the water. Three different environments are typically investigated to cover the range of PWR and 
BWR conditions used in the field, which includes a normal and hydrogen water condition for BWR, Table 2. The major task for aqueous corrosion will be generating long-term ( $\sim 1$-year) corrosion data in order to gain confidence that a new fuel cladding rod will survive the fuel cycle and not contaminate or degrade the reactor performance. The specimens should undergo detailed examination after the 1-year tests to assess the nature of the oxide films. If periodic oxide grains appear one can conclude that the corrosion rate is in a steady-state regime and not transitions that may cause acceleration in corrosion should be expected.

Table 2 Autoclave test conditions.

\begin{tabular}{|c|c|c|}
\hline PWR & $3.57 \mathrm{ppm} \mathrm{H}_{2}$ & $330^{\circ} \mathrm{C}$ \\
\hline BWR-HWC & $0.3 \mathrm{ppm} \mathrm{H}_{2}$ & $290^{\circ} \mathrm{C}$ \\
\hline BWR-NWC & $1.0 \mathrm{ppm} \mathrm{O}_{2}$ & $290^{\circ} \mathrm{C}$ \\
\hline
\end{tabular}

The first series of autoclave corrosion tests should focus on the effect of major alloying elements (i.e. $\mathrm{Cr}$ and $\mathrm{Al}$ ) on the corrosion behavior in the various water chemistry conditions. After this step, the effect of minor alloying elements should be verified to ensure they do not result in accelerated corrosion. These results will support integral fuel tests (Section 4.6) that is the ultimate test of cladding corrosion behavior under in-pile conditions.

\subsubsection{Non-irradiated aqueous corrosion}

\subsubsection{Long term uniform corrosion in PWR/BWR environments}

Activities and Milestones:

FY14

- Uniform aqueous corrosion test for Generation I ATF FeCrAl (2014-2015) (COMPLETE)

FY15

- Quantify mass change and characterize reaction products of Generation I ATF FeCrAl after 1 year exposure in representative PWR/BWR environments and measure crack growth rates under simulated PWR/BWR conditions (2015) (COMPLETE)

FY16

- Uniform aqueous corrosion test for Generation II ATF FeCrAl (2015-2016)

FY17

- Quantify mass change and characterize reaction products of Generation II ATF FeCrAl after 1 year exposure in representative PWR/BWR environments (2016-2017)

\subsubsection{Stress corrosion cracking}

Owing to their bcc crystal structure, $\mathrm{FeCrAl}$ alloys exhibit exceptional resistance stress corrosion cracking under LWR primary coolant environments. In particular, the crack growth rate under these conditions at a given load is roughly two orders of magnitude lower than austenitic alloys. Recent test conducted at GE Global Research Center detail out these observations and are applicable to a wide range of ferritic alloy compositions (FeCr, FeCrAl, and ODS variants) [7]. Therefore, focus should be placed on determining if these alloys are susceptible to IASCC (section 4.3.3). 


\subsubsection{Aqueous corrosion for irradiated material}

\subsubsection{Out-of-pile}

HFIR irradiation of Generation II ATF FeCrAl then out-of-pile aqueous corrosion will be conducted on selected specimens of low irradiation levels.

Activities and Milestones

FY16

- Build water-loop system in rad facility to enable testing of irradiated materials (2016) FY17-20

- Conduct water-side corrosion tests on irradiated Generation II ATF FeCrAl alloys (2017-2020)

\subsubsection{In-pile}

Use data generated form Integral Fuel Test post irradiation examination in section 4.6.

\subsubsection{Irradiation assisted stress corrosion cracking (IASCC)}

Irradiation assisted stress corrosion cracking is another potential degradation mechanism for a new fuel cladding material. Exposure to irradiation for extended periods can change the microstructure and chemistry (e.g. radiation-induced segregation) of steels, thereby reducing their fracture toughness and susceptibility to cracking. Austenitic stainless steels have been extensively studied for IASCC and similar work is needed to assess the susceptibility of $\mathrm{FeCrAl}$ to this form of degradation by measuring crack growth rates and studying the microstructure and chemistry changes under irradiation that may make a material more susceptible to this form of attack.

In-pile IASCC testing is a viable option at Halden reactor. The specimens are placed inside a loop that corresponds to the primary coolant of LWRs. The specimens are attached to bellows that induce stress at a pre-initiated crack as well as an extensometer that measure the crack opening in-pile. The water chemistry conditions (e.g. the amount of dissolved oxygen) can be adjusted in situ in the loop. In this manner detailed IASCC data for FeCrAl alloys can be generated.

Activities and Milestones:

FY16

- Design of IASCC test on optimized Generation II ATF FeCrAl (2016-2017)

FY17

- Irradiation of IASCC test on optimized Generation II ATF FeCrAl (2017-2018) FY18/19

- Post irradiation examination of IASCC test on optimized Generation II ATF FeCrAl (2018-2020)

\subsection{FRETTING}

Fluid flows of high-pressure and high-temperature in the tubes cause oscillating motions between tubes and supports in LWR core. This is called the flow-induced vibration (FIV), which causes fretting wear in contact parts of tube-support, i.e., grid-cladding contacts in nuclear fuel. The flow-induced fretting-wear at fuel cladding-support plate contacts has been a major cause for fuel failure in light water reactors (LWRs). Therefore, it is essential to examine the wear performance of newly developed cladding materials, i.e., $\mathrm{FeCrAl}$ alloys, to implement these in the ATF fuels. 
The fretting research will include three major components: (1) a fundamental, comparative study on general wear resistance of $\mathrm{FeCrAl}$ alloys, (2) capability building for testing in simulated LWR operating conditions, and (3) production of fretting data in the simulated LWR conditions to provide knowledge base for predicting the fretting behavior of ATF cladding materials.

\subsubsection{Non-irradiation fretting properties}

\subsubsection{Wear resistance}

Basic wear/fretting tests for advanced cladding materials

Basic wear resistance is performed for advanced cladding materials using a reciprocating wear testing machine (TR-282 Ducom). The results are used to compare the general wear resistance among the cladding candidate materials including the newly developed $\mathrm{FeCrAl}$ alloys and the traditional Zir-4. Relative wear resistance between dissimilar materials is also examined. For the wear testing in the Ducom system, reciprocating friction monitor is specially designed to study friction characteristics of materials. A reciprocating engine is used to create one directional sliding motion between the samples while a loading mechanism applies the desired load on the test samples. Friction and wear evaluation can be performed under dry or lubricated (water) conditions for tube on tube contacts. Further, optical analysis and evaluation of tribological properties of newly developed materials will be performed.

Activities and Milestones

FY14

- Do wear test on Generation I ATF FeCrAl (2013-2014) COMPLETE

- Report on the room temperature wear properties for advanced cladding materials 2014 COMPLETE (journal paper in review [6])

Production of wear and fretting test data for computational simulation input and for performance assessment

Fretting wear tests will be performed for the FeCrAl alloy grid-cladding pairs in the specially built test facility for simulating PWR core vibration conditions (section 4.4.1.2). The objective of the testing in the simulated PWR conditions is to examine the resistance of the new materials to grid-to-rod fretting and to provide database for assessment of fuel performance in normal operation condition. Since the implementation of the new ATF fuel requires a guarantee to not aggravate the fretting wear induced fuel failure, the relative fretting resistance of the $\mathrm{FeCrAl}$ alloys over the $\mathrm{Zr}$-alloys will be particularly empathized in the simulation testing and evaluation.

Influence of some variables on fretting-wear behavior will be explored. An evaluation of grid-to-rod fretting will be performed by considering the variation in the flow field with different spacer grid geometries. The grid-to-rod fretting behavior is evaluated by relating the actuator-rod vibration condition with different simulated primary coolant conditions and the variations in the contact conditions. The effects of vibration frequency, load, and displacement will be tested by changing actuator operation condition and internal jig design. The influence of changes in material condition and contact surfaces will be also examined to provide feedback for tube manufacturing process.

Activities and Milestones:

FY16

- Report on the comparative fretting behavior of advanced cladding materials in simulated PWR conditions (2015-2016)

FY17 
- Report on the detailed fretting behavior of FeCrAl alloy cladding in simulated PWR conditions (2016)

\subsubsection{Fretting test facility}

Under the LWR core conditions the grid-to-rod fretting wear is one of the main causes of fuel failure. In the current $\mathrm{Zr}-4$ cladding and grid assembly one of the main variables determining the fretting wear resistance is the spacer grid geometry. Changing cladding material (and grid material) to the $\mathrm{FeCrAl}$ alloys may lead to different fretting wear behaviors, and thus may require changes of spacer grid design and even surface treatment conditions. Therefore, to access the performance of the newly developed $\mathrm{FeCrAl}$ alloys in normal operation, the resistance of the new alloys to the fretting-wear induced fuel failure needs to be examined. The objective of this work is to build a testing facility that can generate the simulated FIV conditions for reactor core for testing fretting phenomena with the new ATF cladding materials.

Since the generation of full scale fretting failure condition is costly, the approach in this work will be a laboratory scale simulated testing facility. A test station consisted of an autoclave device providing a high temperature and high pressure environment, an external actuator for vibrational motion, internal structures for applying simulated fretting loads to specimen contacts, and load (or displacement) and temperature monitoring/data acquisition system, will be built for the simulated testing. The detailed simulated-fretting conditions, i.e., normal and sliding loads, stroke, and frequency, need to be determined based on previous tests and computer simulation results on PWR core.

Tasks and Milestones:

FY16

- Build a fretting test facility for simulation of PWR condition (2015-2016)

\subsubsection{Fretting of irradiated material}

Fretting under irradiation conditions will be investigated during the Lead Test Rod (LTR) test that will take place in a commercial reactor.

\subsection{TRITIUM}

In fission reactors, tritium can be produced via a multitude of pathways, but reactor inventory is dominated by ternary fission in fuel rod and neutron absorption by boron in pressurized water reactors. In boiling water reactors, the sole significant source of tritium is the fuel, due to the absence of boron in primary coolant. Tritium release is occasionally observed at current reactors but is generally limited in those reactors utilizing zirconium alloy fuel claddings due to the strong chemical affinity of zirconium for hydrogen and the extremely low tritium permeability of zirconium oxide. Any increase in the extent of release from the fuel will be directly proportional to the increase of the tritium inventory in the primary coolant and the tritium releases to the environment, which is directly related to the cladding types. Note that hydrogen permeability of BCC (body-centered-cubic) iron alloys is known to be higher than FCC (face-centered-cubic) variants. Thus one can conjecture that for the proposed FeCrAl alloy, an advanced oxidation-resistant iron-based alloy for the ATF application, the tritium level in primary coolant will be even higher compared to the historic nuclear power plants using austenitic stainless steel fuel clad, and, of course, higher than the current LWRs, raising safety concerns. Therefore, detailed investigation of tritium permeation in $\mathrm{FeCrAl}$, as well as effective mitigation strategies, must be carried out before ATF cladding concepts can be further developed and refined. 
The minor alloying elements in the Generation II ATF FeCrAl alloys, which are in solution with the metal matrix, do not affect the crustal structure and lattice parameter of FeCrAl alloys significantly. Therefore, it is not expected that they will have an impact on tritium transport behavior in these alloys. Therefore, the data from Generation I ATF FeCrAl alloys should be applicable to the later generations.

The major outputs will be the determination of hydrogen permeability of FeCrAl alloys and the mitigation strategy for ATF application, which will be summarized in the form of a journal paper.

\subsubsection{Non-irradiated material testing}

\subsubsection{Build facility}

The first step of this work is to determine hydrogen permeability of $\mathrm{FeCrAl}$ alloys. A permeation test facility is needed to perform hydrogen permeability measurements for different alloys. The system is verified by $304 \mathrm{SS}$, of which the hydrogen permeability has been studied intensively.

Activities and Milestones:

FY13

- Design and construction of hydrogen permeation test system (2013-2014) (COMPLETE)

FY14

- Hydrogen permeation measurements of 304 SS claddings used to verify the system (2014)

(COMPLETE)

\subsubsection{Testing of first generation FeCrAl}

Then three different FeCrAl claddings (T35Y2, T54Y2, APMT) will be tested to obtain the hydrogen permeability of $\mathrm{FeCrAl}$ alloys. The hydrogen permeation activation energies and pre-factors will be determined.

Activities and Milestones:

FY14

- Hydrogen permeation measurements of Generation I ATF FeCrAl claddings (2014)

(COMPLETE)

\subsubsection{Mitigation strategy of tritium permeation of FeCrAl}

The hydrogen permeability of alumina is known to be extremely low, so an adherent and dense alumina layer on the surface of $\mathrm{FeCrAl}$ cladding will mitigate the tritium permeation in fission reactors. Thus, the controlled oxidation conditions for this required oxide layer should be clarified to identify mitigation strategies for normal operation conditions.

Activities and Milestones:

FY14

- Pre-oxidation of Generation I ATF FeCrAl claddings to form stable $\mathrm{Al}_{2} \mathrm{O}_{3}$ as protective (2014) (COMPLETE)

- Hydrogen permeation of oxidized Generation I ATF FeCrAl claddings (2014) (COMPLETE)

- SEM characterization of scale thickness of pre-oxidized Generation I ATF FeCrAl (2014) (COMPLETE) 


\subsubsection{Hydrogen solubility and diffusivity of FeCrAl}

The hydrogen permeability is a product of solubility and diffusion. So once two of these three parameters are determined, the third one can be calculated. In this section, hydrogen solubility of FeCrAl will be determined by using thermogravimetric analysis. Given the diffusivity of hydrogen in $\mathrm{FeCrAl}$, the hydrogen distribution across the cladding can be predicted by developing a diffusion model, giving rise to the prediction of potential hydrogen leakage.

Activities and Milestones:

FY14

- Hydrogen solubility measurements of Generation I ATF FeCrAl alloys using TGA (2014) (COMPLETE)

- Modeling hydrogen distribution in FeCrAl cladding under normal operation environment (2014) (COMPLETE)

\subsection{INTEGRAL FUEL TEST}

\subsubsection{Irradiation of FeCrAl clad $\mathrm{UO}_{2}$ fuel in the Halden ATF test rig}

The second activity relates to irradiation of FeCrAl clad $\mathrm{UO}_{2}$ fuel in the Halden ATF test rig. Similar with the in-pile creep test data, this test will be essential to and supportive of the qualification data-package for the eventual application of FeCrAl as an LTR in a commercial LWR. The test rig for this experiment generally consists of six rodlets that could be a mixture of various cladding materials and configurations. In case of $\mathrm{FeCrAl}$ cladding, the concept is to be tested as fueled rodlets. The fuel pellets for the rodlets are to be supplied by Halden Reactor Project or potentially an industrial partner (Westinghouse Sweden). During this baseline irradiation the fuel temperature, rod internal pressure, and power are continuously monitored. The final configuration of the test rig could allow specialized sensors such as cladding elongation sensor. This capability will allow determination of the onset of pellet-cladding contact as a function of power during irradiation. The test rig is continuously monitored to detect breach of the cladding (i.e. fuel failure). After sufficient burnup accumulation, the rodlet(s) will undergo PIE to determine the extent of cladding corrosion, pellet clad interaction (PCI), and any other potential degradation modes. These rodlets could also be utilized in an in-pile LOCA test at Halden (i.e. IFA-650 rig at the Halden reactor that has been used successfully for 14 in-pile LOCA tests so far).

Activities and milestones

FY14

- M3FT-14OR0202354 Issue report summarizing Halden Project Group activities related to ATF (06/15/2014) COMPLETE

- M2FT-14OR0202352 Issue report summarizing Planning and Fabrication of ATF cladding in support of Halden Irradiation. 9/2/2014 (COMPLETE)

FY15

- Design of integral fuel test irradiation of Generation II ATF FeCrAl and UO2 (2015-2016)

- M2FT-15OR0202353 Issue report summarizing design and initial results from Halden Irradiation on US-contributed ATF candidate materials 3/16/2015 (COMPLETE)

FY16

- Irradiation of integral fuel irradiation test of Generation II ATF FeCrAl and UO2 (2016-2019) FY19/20

- Post irradiation examination of integral fuel irradiation test of Generation II ATF FeCrAl and UO2 (2019-2021) 


\section{OFF NORMAL ENVIRONMENTAL EFFECTS}

\subsection{LOSS OF COOLANT ACCIDENTS}

During loss of coolant accidents (LOCA) fuel cladding can balloon and experience burst due internal gas pressure and increased creep and lowered strength at high temperatures. The rate and degree of high temperature deformation could affect the heat transfer from fuel to coolant. Since both oxidation and irradiation (lingering irradiation defects in the cladding as temperature increases as well as chemical effects from contact with the fuel pellet) can alter the properties of cladding, i.e., reduces ductility, the burst behavior can alter after irradiation. Cladding burst leads to the release of gaseous and volatile fission product inventory in the fuel. Therefore, understating the burst behavior of the cladding and the effects of irradiation and oxidation is critical in determining the accident response of the integral fuel rod. In selection of an ATF cladding material, therefore, an optimum combination of high temperature deformation and failure resistance is critical to delay and minimize cladding failure.

Initially as-fabricated cladding tubes will be tested under an integral LOCA sequence to determine the burst temperature as a function of rod internal pressure. The cladding configuration after burst will be evaluated to determine any significant changes in microstructure and the extent of oxidation. Post-quench ductility of the cladding, a parameter of great importance for maintaining a controllable and coolable core, will then be evaluated.

Following this task, irradiated rodlets should be tested under a similar sequence. For this purpose ATF-1 pins, irradiated at ATR are ideal. In this manner, determination of the effect of FCCI on the high temperature burst properties of the $\mathrm{FeCrAl}$ clad in the presence of fission gas is possible.

Finally, in a more comprehensive manner, the FeCrAl clad rodlets, irradiated long-term at Halden baseline irradiation test rig could be tested under an in-pile LOCA sequence. Halden reactor is wellexperienced in these tests (IFA-650) with 14 tests carried out to date. This test involves re-instrumentation of the irradiated rodlet into the LOCA test rig at the hot-cell facilities in Kjeller. The re-instrumented rig can then be irradiated and ultimately tested under LOCA conditions in-pile in the Halden reactor. These results, can complement the in-cell LOCA tests at SATS (5.1.2.1).

The high temperature deformation during the above postulated accidents should belong to a high rate creep phenomenon driven by high stress and temperature. Since the high temperature mechanical behavior of cladding is a particularly important factor in selection of ATF cladding and processing route, the high temperature properties of cladding materials will be investigated under two scopes: (1) High temperature tube burst testing for ATF cladding materials to provide data for structural behaviors in simulated accident conditions. (2) The effects of microstructural parameters including grain size on high temperature burst resistance.

\subsubsection{Non-irradiated testing}

\subsubsection{High temperature environment testing and visualization}

Thin-walled tube testing technology based on visual imaging and analysis is available to examine the behaviors of pressurized tube specimens at high temperature simulating fuel cladding behaviors under normal and accident conditions. The testing method can prove useful and be capable of deformation and

burst testing in a wide temperature range of $300-1200{ }^{\circ} \mathrm{C}$. In FY 2013 a PC-controlled recording device 
has been developed to record diametrical change (hoop strain) and temperature simultaneously. The high temperature tube testing equipment is further improved for accommodating various diameters of pressurized tube specimens. The in-situ strain measurement method using high temperature video camera and light filtering system will be established. This method uses pressurized thin-walled tube specimens, and the specimen design and fabrication method, fine machining and electron beam welding, will be established.

To demonstrate the capability of the in-situ tube burst testing facility and to perform a comparative study for the newly developed cladding candidate materials, a campaign of high temperature tube burst testing will be performed. Pressurized thin-walled tube specimens will be fabricated from the first (and second) generation $\mathrm{FeCrAl}$ alloys and tested at high temperatures. The in-situ creep data and high temperature strength data will be calculated and the new data will be analyzed and compared with the database for Zircaloy-4 claddings. The tube deformation and burst testing will be also performed for the ultrahigh strength ODS materials and compared to the behaviors of FeCrAl alloy cladding tubes. This tube burst testing for ODS steel tube specimens is expected to be performed at much higher temperature when compared to the testing for lower strength cladding materials.

Activities and Milestones:

FY14

- Develop in-situ burst testing facility (2013-2014) COMPLETE

- Test Generation I ATF FeCrAl and other alloys in in-situ burst testing facility 2013-2014 (COMPLETE)

- M3FT-14OR0202281/M3FT-15OR0202293 Thin-walled tube testing and evaluation technology and high temperature burst tests for advanced cladding materials/ Report on tube deformation and burst testing and test technology development 11/20/3014 (COMPLETE)

\subsubsection{Rapid ramp test in oxidizing environments}

An integral LOCA test facility will be build to perform LOCA integral burst and quench test according to NRC requirements.

High temperature tube burst testing, in the presents of steam atmosphere, will be performed on ATF cladding material. Detailed analysis will be performed to provide database to the performance assessment analyses for the fuel channel/bundle in accident conditions. The creep measurement components will be built combining with LOCA furnace to allow the creep test inside steam conditions. Improvement of tube visibility inside the steam by the high temperature camera would be the key.

Activities and Milestones:

FY13

- Design and build out of cell LOCA integral furnace facility 2012-2013 (COMPETE)

FY14

- Test Generation I ATF FeCrAl materials 2013-2014 (COMPLETE)

FY15

- $\quad$ Test Generation II ATF FeCrAl materials 2014-2015 (IN PROGRESS)

- Upgrade LOCA furnace capability to enable in-situ measurement of creep 2014-2015 (IN PROGRESS)

FY16

- Test Generation II ATF FeCrAl materials in upgraded LOCA furnace 2015-2016 (IN PROGRESS) 


\subsubsection{Irradiation testing}

\subsubsection{In-cell LOCA Testing}

A LOCA integral test facility to be used in hot cells on fueled materials will be build according to NRC requirements to enable LOCA burst and quench test on fueled materials.

Activities and Milestones:

FY14/15

- Design and construct in-cell LOCA integral test facility 2013-2015 (IN PROGRES)

- M3FT-14OR0202034 Complete safety and QA evaluation of integral LOCA module operation in hot cell 09/30/2014 (COMPLETE)

- M2FT-15OR0202311 Report on final assembly, safety documentation, and approvals for fully operational in-cell Severe Accident Test Station 9/30/2015 (IN PROGRESS)

FY16

- Upgrade facility to measure in-situ creep during LOCA test (2015-2016)

- Design and build in-cell infrastructure to support building of test trains for LOCA test (2016) FY17

- Install system into hot cell (2016-2017) - Dependent on when material is available for testing, which is dependent on ATR schedule

- Test ATF-1 Generation II ATF FeCrAl and $\mathrm{UO}_{2}$ rodlets with low and medium burn-up (20162020)

\subsubsection{In-pile LOCA test}

This test involves re-instrumentation of the irradiated integral fuel rodlet (Section 4.6) into the LOCA test rig at the hot-cell facilities in Kjeller. The re-instrumented rig can then be irradiated and ultimately tested under LOCA conditions in-pile in the Halden reactor.

Activities and Milestones

FY19/20

- In-pile LOCA test of Halden irradiated baseline rods (2019-2020)

\subsubsection{High temperature properties}

High-temperature melt behavior of the $\mathrm{FeCrAl}$ alloys and their oxides are important parameters that need to be evaluated. Specifically, these parameters are direct inputs into severe accident analysis codes that are used to specific the onset of core relocation during the course of such computations. The melting behavior of these alloys and their oxides can be determined using a Simultaneous Thermal Analyzer (STA). Differential scanning calorimetry (DSC) techniques in such an instrument can be directly utilized for this purpose. Since all the irradiation damage is annealed away upon approaching melting temperatures, there is no need to evaluate irradiated materials.

Activities and Milestones:

FY16

- Determine the melting point of Generation II ATF FeCrAl alloys and their oxides as a function of major and minor alloying constituents and compare against thermodynamic database predictions (2015-2016) 


\subsubsection{Multiple rod QUENCH test}

The integral burst, oxidation, and potential melting behavior of the FeCrAl clad fuel assembly needs to be evaluated. This test can be carried out most suitably at KIT's QUENCH facility, described in detail in reference [8]. Briefly, an array of $\sim 20$ rods, $2 \mathrm{~m}$ in length are tested in flowing steam. The rods are heated internally using tungsten heating elements that are placed inside alumina pellets and clad in $\mathrm{FeCrAl}$ cladding.

Activities and Milestones:

FY16/17

- Supply FeCrAl cladding and grid and carryout multi-rods QUENCH test at KIT facility, (20162017)

FY18

- Carry out multi-rods QUENCH test (2017-2018)

\subsection{REACTIVITY-INITIATED ACCIDENT}

An important class of design basis accidents that need to be considered are reactivity insertion accidents (RIA). The basis for regulatory criteria for RIAs dates back to the 1970s and they aim to set a maximum limit on energy deposition in the fuel during the transient. The failure mechanism for the current fuel systems under an RIA is a function of burnup: at low burnups $(<40 \mathrm{MWd} / \mathrm{kgU})$, post-departure from nucleate boiling (DNB) phenomena is limiting, whereas at higher burnups, pellet-cladding mechanical interaction (PCMI) is the dominant failure mechanism. In case of the latter, the fuel pellet heats up in a near adiabatic manner and expands accordingly. During this rapid transient, the cladding remains at the same temperature and start to experience significant stresses due to expansion of the pellet.

In a much longer time scale, pellet-cladding mechanical interaction can take place during power ramps. Once again, the increase in the pellet power causes it to expand and exert mechanical forces on the cladding. This could result in cladding to fail.

Therefore extensive testing over a wide range of power pulse periods and ramps is necessary to examine the behavior of thin FeCrAl cladding under these scenarios.

\subsubsection{Fuel clad mechanical interaction}

Under power ramps and Reactivity Insertion Accidents (RIAs), pellet expansion and mechanical interaction with the cladding can result in cladding failure. This susceptibility grows as burnup increases in the fuel, pellet swells results in the reduction/closure of the pellet-clad gap, and the cladding embrittles as a result of irradiation. The onset of failure (i.e. load) needs to be quantified for unirradiated and irradiated cladding. This can be achieved by plug/mandrel expansion tests [9]. Initially unirradiated cladding is used. Later on, neutron irradiated cladding segments are necessary to capture the embrittlement due to irradiation. These results can then be fed into fuel performance codes to design constraints and operational guidelines. Cladding segments can be irradiated in HFIR. Ultimately transient testing in the reactor is necessary that will be carried out at TREAT reactor in Idaho.

Activities and Milestones:

FY16

- Plug/mandrel expansion tests: non-rad capability set-up for non-irradiated materials (2015-2016)

- Plug/mandrel expansion test on optimized Generation II ATF FeCrAl (2016)

FY17 
FY18/19

- Plug/mandrel expansion test capability set-up for irradiated materials in hot cell facility (2017)

- Plug/mandrel expansion tests on HFIR irradiated optimized Generation II ATF FeCrAl thin tubes (2018-2019)

FY19/20

- $\quad$ TREAT testing of fresh and irradiate fuel (2019-2020).

\subsection{MELT AND RELOCATION}

\subsubsection{Fuel Relocation}

\subsubsection{Cladding Degradation Sequence and Eutectic Formation}

Determine possible eutectic formation between various material combinations present in core (fuel, cladding, structural material, control material, neutron poison material). Determine initiation (temperature) and sequence of fuel failure, degradation and relocation.

Activities and Milestones:

FY16

- Small-scale separate effects experiments investigating eutectic formation among various core materials and Generation II ATF FeCrAl cladding in HTF module of SATS (2015-2016)

- Small integral experimental determination of degradation modes for single pin to melt in HTF module of SATS (2015-2016)

FY17

- Integral full bundle (with all constitutes), degradation and melt behavior as part of multiple rod QUENCH test (section 5.1.4) (2016-2017)

\subsubsection{Cladding Oxide Properties}

The properties (strength and thermophysical) of the cladding oxide(s) are required for severe accident analysis. Oxide properties can affect melt relocation/accident progression (e.g. TMI-2) and engineering safety features for severe accidents (e.g. in-vessel retention in AP-1000).

Activities and Milestones:

FY16/17

- Oxidize optimized Generation II ATF FeCrAl tubing in SATS 2016 (section 5.5.1)

- Measure oxide properties of Generation II ATF FeCrAl tubing (2016)

- Report on the cladding oxide properties of Generation II ATF FeCrAl tubing (2016-2017) FY19/20

- Oxidize optimized Generation II ATF ODS FeCrAl tubing in SATS 2019 (section 5.5.1)

- Measure oxide properties of Generation II ATF ODS FeCrAl tubing (2019)

- Report on the cladding oxide properties of Generation II ATF ODS FeCrAl tubing (2019-2020)

\subsection{CLADDING LEAK UNDER NORMAL OPERATION}


It is plausible that under normal operating conditions, the cladding fails and provides a pathway for the primary coolant to enter the rod. In case of standard fuel, oxidation of $\mathrm{UO}_{2}$ to $\mathrm{U}_{3} \mathrm{O}_{8}$ is not an issue (due to the high local hydrogen activity) and the main concern is the internal oxidation of the cladding and the ensuing secondary hydriding [10]. The extent of radionuclide release from the rod is governed by the inventory at the time and the size of the cladding flaw and the extent of fuel pellet damage. In case of FeCrAl clad fuel, the cladding will not oxidize at a similar rate as $\mathrm{Zr}$-based alloy and the resulting hydrogen gas partial pressure can be lower. Therefore, the pellet might oxidize to $\mathrm{U}_{3} \mathrm{O}_{8}$. This behavior needs to be assessed.

Activities and milestones:

FY17/18

- Conduct experiments on high-pressure hydrothermal corrosion of optimized Generation II ATF $\mathrm{FeCrAl}$ clad- $\mathrm{UO}_{2}$ at elevated temperatures $\left(200-400^{\circ} \mathrm{C}\right)$. The results from autoclave testing on Generation I ATF FeCrAl, already carried out in FY15 (section 4.3.1.1) can be used for calculating the extent of material degradation under these conditions. (2017-2018)

- Estimate the extent of fuel degradation during residence time in the core assuming it's in contact with liquid water. (2018)

\subsection{HIGH TEMPERATURE STEAM OXIDATION}

The critical issue for a severe accident is minimizing the heat and hydrogen generation due to the reaction between the fuel cladding and the reactor water. As the temperature increases during an accident and steam generated, this reaction becomes more aggressive. It should be recognized that thermodynamically oxides are favored so the oxidation reaction of metals to oxides will proceed for any structural material. However, the reaction kinetics can be minimized by the formation of a stable, slow growing reaction product or scale. While $\mathrm{ZrO}_{2}$ is a fast oxygen conductor and nearly transparent to the transport of oxygen, $\mathrm{Al}_{2} \mathrm{O}_{3}$ (as well as $\mathrm{Cr}_{2} \mathrm{O}_{3}$ and $\mathrm{SiO}_{2}$ ) can act as a solid state diffusion barrier and limit the reaction. Alumina is particularly favorable because of its high thermodynamic stability, especially in the presence of steam. When a protective alumina scale is formed, the steam oxidation reaction becomes limited by transport through the scale. As the reaction proceeds and the scale thickens, the $\mathrm{O}$ diffusion distance increases and the reaction slows. This is the basis of parabolic kinetic rates.

Carl Wagner established the two criteria for selective oxidation by which an alloy A-B with B the more thermodynamically stable oxide forms a protective external BOx oxide. In general, a critical level of B is defined, $\mathrm{B}^{*}$, above which a protective scale forms. The first criteria for $\mathrm{B}^{*}$ is that there be sufficient $\mathrm{B}$ to form the layer and the second criteria is that the reaction proceed slowly enough to maintain the layer. These criteria are fairly well established for Fe-base alloys such as $\mathrm{Fe}-\mathrm{Cr}, \mathrm{Fe}-\mathrm{Al}$ and $\mathrm{Fe}-\mathrm{Cr}-\mathrm{Al}$ in an oxidizing environment such as ambient air. In the latter case, there is still some disagreement about the exact nature of the beneficial role of the "third" element, in this case $\mathrm{Cr}$, which is of intermediate stability between Fe and $\mathrm{Al}$. Likewise, there is not complete understanding about the role of $\mathrm{H} 2 \mathrm{O}$ in oxidation. However, it is generally agreed that steam is a more aggressive environment than air and that alloys tend to behave as if they contain less $\mathrm{Cr}$ and $\mathrm{Al}$ in steam compared to oxidation in dry air or $\mathrm{O}_{2}$. Thus, conventional wisdom about the necessary $\mathrm{Cr}$ and $\mathrm{Al}$ contents for protective behavior for $\mathrm{FeCrAl}$ alloys does not apply to steam. Another complicating issue is that oxidation studies are typically performed at a constant temperature where oxide thickness or mass change is used to study kinetics or the effect of composition. For most accident scenarios, the temperature is not constant and one of the most relevant, a rarely considered, issues is the maximum temperature at which the alloy can still continue to form a protective scale. For FeCrAl, one the alloy can no longer form alumina, it is likely to begin reacting with steam to form $\mathrm{FeOx}$, approximately $1000 \mathrm{X}$ faster and similar to the oxidation rate of $\mathrm{Zr}$-based alloys. 
A high temperature furnace with the capability of testing materials up to $1700^{\circ} \mathrm{C}$ will be constructed to simulate high temperature steam oxidation accidents.

This system will be constructed for non-irradiated materials as well as irradiated materials. The High Temperature Furnace (HTF) will be part of the Severe Accident Test Station that will also include the LOCA furnace (section 5.1).

\subsubsection{Steam oxidation under non-irradiated conditions}

Activities and Milestones:

FY12/13

- Design and construct high temperature furnace for steam oxidation out-off-cell 2012-2013 (COMPLETE)

- Test Generation I ATF FeCrAl coupons 2012-2014 (COMPLETE)

FY14

- Test Generation II and ODS ATF FeCrAl coupons 2014-2015 (IN PORGRESS)

- Steam Testing of ATF Alloys to 1200C While Measuring $\mathrm{H}_{2}$ Evolution 2013 - 2015 (IN PROGRESS)

- Develop Procedure for Steam Testing Protocol and provide to ORNL 2013-2014 (COMPLETE)

- Computational thermodynamic and diffusion kinetic modeling of FeCrAl oxidation 2013-2014 (COMPLETE)

FY15

- M3FT-15OR0202342 Complete summary report and data compendium of FeCrAl oxidation kinetics 8/28/2015 (IN PROGRESS)

FY16

- Testing of optimized Generation II ATF FeCrAl tubes (2015-2016)

- Report on oxidation kinetics for optimized Generation II ATF FeCrAl tubes (2016) FY19/20

- Testing of optimized Generation II ATF ODS FeCrAl tubes (2019-2020)

- Report on oxidation kinetics for optimized Generation II ATF ODS FeCrAl tubes (2020)

\subsubsection{Steam oxidation under irradiated conditions}

FY14

- Construct in-cell high temperature furnace for steam oxidation on irradiated material 2013-2014 (COMPLETE)

- M2FT-14OR0202036 Complete in-cell installation of High-Temperature capability for Severe Accident Test Station. 11/28/2013 (COMPLETE)

FY15

- M2FT-15OR0202311 Report on final assembly, safety documentation, and approvals for fully operational in-cell Severe Accident Test Station 9/30/2015 (IN PROGRESS)

FY19/20

- Steam oxidation of optimized Generation II ATF FeCrAl thin tube irradiation (2019-2020)

(material from section 4.2.1)

FY20/21

- Steam oxidation of optimized Generation II ATF ODS FeCrAl thin tube irradiation (2020-2021)

(material from section 4.2.1) 


\section{SYSTEM ANALYSIS}

Successful deployment of FeCrAl alloys as LWR fuel cladding requires system analysis incorporating separate and integrated analyses for multiple disciplines and operational conditions. The transition from the existing LWR fuel/cladding system of $\mathrm{UO}_{2} /$ Zircaloy to an ATF fuel/cladding concept will include multiple stages as the core design moves through successive phases: an equilibrium $\mathrm{UO}_{2} /$ Zircaloy core, a mixed transition core containing $\mathrm{UO}_{2} /$ Zircaloy and $\mathrm{ATF}$ (e.g., $\mathrm{UO}_{2} / \mathrm{FeCrAl}$ ) assemblies, an initial all-ATF core, and an equilibrium all-ATF core. This document focuses primarily on analyses of an equilibrium all-ATF $\mathrm{UO}_{2} / \mathrm{FeCrAl}$ reactor core. The predicted performance of the equilibrium ATF core and fuel design will dictate whether the performance of the fuel and system are attractive enough for utilities to adopt the ATF fuel.

The analyses span disciplines including reactor physics (neutronics), thermal-hydraulics $(\mathrm{T} / \mathrm{H})$, thermomechanical fuel performance (FP), and core components and chemical interactions $(\mathrm{CC}+\mathrm{CI})$ including severe accident (SA) analysis and coolant chemistry. All of these analyses will be integrated to establish a baseline fuel rod and assembly design that satisfies general constraints for a "one-to-one" replacement fuel assembly (boundary conditions) and seeks to achieve certain objectives (performance metrics).

Successful ATF concepts must maintain the performance achieved by existing fuels during normal steady-state operation and provide enhanced safety margin over existing fuels with respect to design basis and beyond design basis accidents. In addition, a new cladding must meet regulatory licensing criteria for design basis accidents (DBAs). DBAs and beyond design basis accidents (BDBAs) involve the entire core, primary system, emergency core cooling system, as well as other engineered systems and barriers. The accidents also involve the integral effects of various phenomena. System-level analysis of design basis and beyond design basis accidents is required to demonstrate the gains afforded by ATF concepts.

Requirements and constraints of a "drop in" replacement fuel assembly include conforming to existing fuel rod and assembly/bundle geometries, using $\mathrm{UO}_{2}$ fuel pellets, maintaining internal assembly/bundle configurations and layouts, and maintaining the same core thermal power. Standard fuel rod dimensions (e.g., from a Westinghouse $17 \times 17$ PWR fuel assembly or GE14 BWR fuel bundle) must be maintained when moving to $\mathrm{FeCrAl}$ cladding, including fuel rod outer diameter and rod-to-rod pitch in order to stay within the same assembly/bundle footprint and minimize impacts on thermal-hydraulic behavior and performance.

Objectives to be considered performance metrics and therefore chosen to yield an attractive baseline design include operational factors such as:

- maintaining the same cycle length (in units of effective full power days) as could be achieved by using zirconium-alloy cladding in a given system,

- maintaining the same number of reload batches used for core refueling, and

- maintaining the uranium enrichment (including in peak enrichment pins or assemblies) below the existing 5\% limit in place for many fuel cycle facilities and activities (e.g., storage and transportation), or if enrichments above 5\% are needed demonstrate why this might be acceptable for various facilities and activities (e.g., an enrichment above 5\% in a particle-based fuel could have the equivalent or lower mass of U-235 per total fuel assembly volume and thus potentially satisfy criticality safety requirements).

It should be noted that the items identified above are objectives, not requirements; some designs could, for example, require reduced cycle lengths or increased enrichment levels but still prove to be an overall 
attractive baseline design and be acceptable to vendors and utilities. These tradeoffs would have to be investigated and justified.

As noted above, the performance of the ATF design must be evaluated over a range of conditions and events. The categorization of the classification of an event during the operation of a nuclear reactor is primarily based on the frequency of the event occurring, and the identification of the radiological damage as a frequency of the occurrence. The details of the approach are not defined here, but in general the approach includes the identification of possible (more than credible) events (internal and external) that challenge the fission product barriers under all operational conditions. These include:

- Identifying the barrier failure mechanisms in the fuel, clad, reactor vessel, and containment

- Identifying the physical process(es) driving the failure e.g., thermal overpower such as rod ejection, fast boron dilution, flow reduction, heat increase etc.

- Identifying the physical process driving the failure e.g. Crack growth, overpressure

- Identifying scenarios for the groups of failures, and postulate the initiating events driving these scenarios e.g., increase in steam flow, or decrease in feed water temperature etc.

The categorization is then based on the frequency of the initiating event, determining the bounding assumptions on the postulated initiating event, and the consequences. There are a number of applicable technical standard and regulations and guides that outline this in detail such as ANSI/ANS 51.1, NRC 10 CFR 50, and the NUREG 0800 standard review plan. A summary of the categories from different bodies can be seen below:

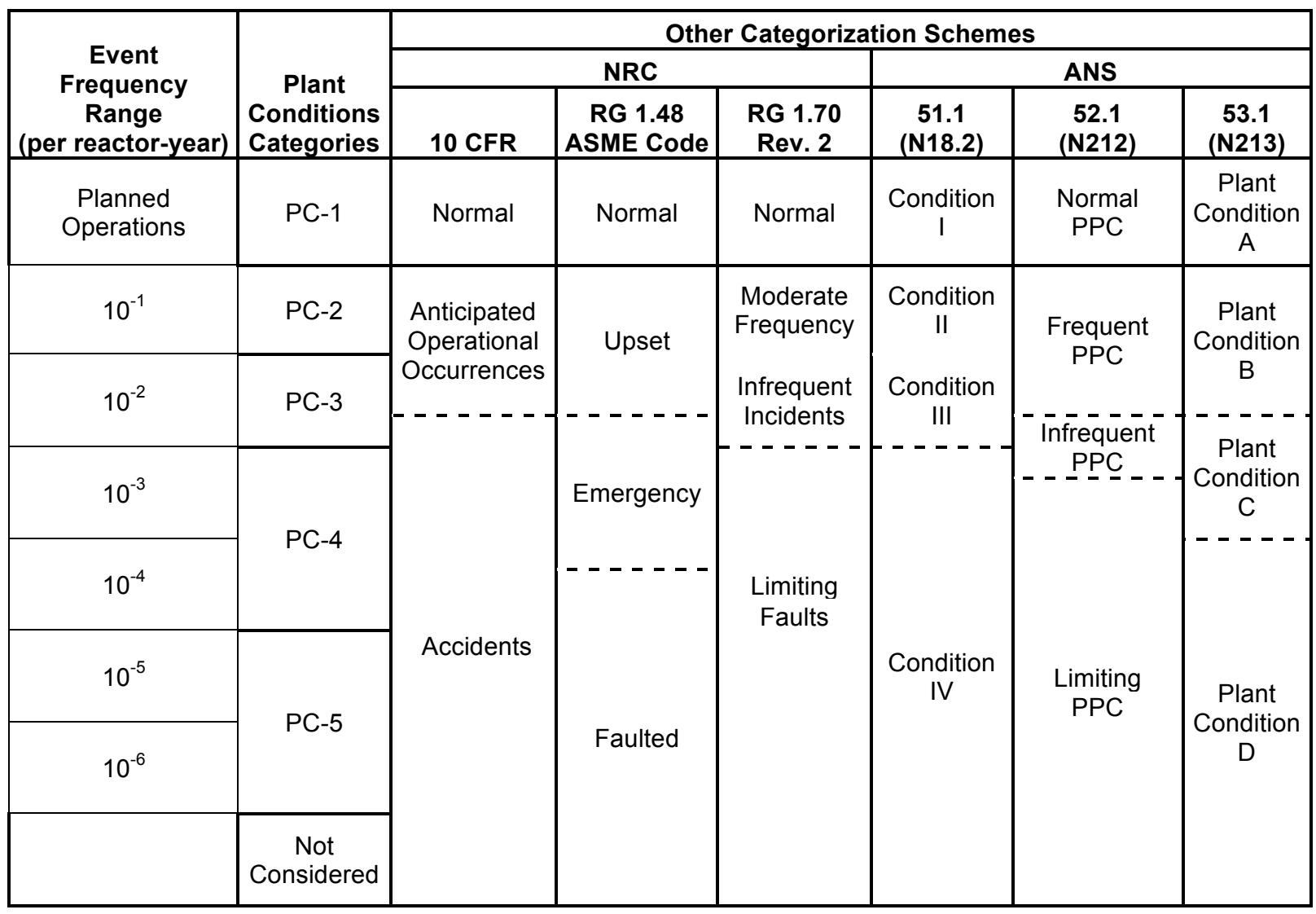


Therefore, in order to define the scope of the design and analysis work required for ATF systems assessment, the analysis scope outlined below has been described based on these different event classifications, in particular:

- Normal Operation (NO)

- E.g. Startup, shutdown (hot and cold), refueling, hot standby, power operation (including load follow)

- Anticipated Operating Occurrences (AOOs), arrested by the protection systems

- E.g. Inadvertent control rod withdrawal, partial loss of reactor coolant flow, control rod drop, reactor coolant system depressurization, reactor or turbine trip, chemical shim dilution

- Design Basis Accidents (DBAs)

- Examples: small-break loss of coolant accident (SB-LOCA), single reactor coolant pump locked rotor, control rod ejection

- Beyond Design Basis Accidents (BDBAs)

- Example: loss of coolant accident without safety injection (LOCA without SI), loss of coolant accident with station blackout (LOCA with SBO)

With each of the phases of work outlined below, a more rigorous and involved set of analyses are considered as the technology options are evaluated, screened and developed. These analyses types are similar to the fundamental design and licensing calculational sequence that would form part of an eventual submittal by the licensee to insert a lead test rod (LTR) for irradiation in a commercial LWR; however, the purpose of this TIP and therefore the analysis program outlined below in Section 5.1 is not the design and licensing work itself but rather to provide confidence in the $\mathrm{UO}_{2} / \mathrm{FeCrAl}$ ATF concept before significant investments of time and money are made for licensing efforts. The results from these analyses should be documented and shared with the licensee to support their licensing analyses, but LTR analysis would need to be performed separately by the reactor licensee in conjunction with the vendor using approved methodologies and codes, and submitted to the NRC by the licensee of the reactor in question.

Future work not described below should also include the previous mentioned transition analyses moving from an equilibrium $\mathrm{UO}_{2}$ /Zircaloy core to a mixed transition core containing $\mathrm{UO}_{2} /$ Zircaloy and ATF (e.g., $\mathrm{UO}_{2} / \mathrm{FeCrAl}$ ) assemblies, then an initial all-ATF core, and finally an equilibrium all-ATF core. Lastly, it must be noted that all of the analyses described below focus on reactor operation of $\mathrm{UO}_{2} / \mathrm{FeCrAl}$; front end (e.g., mining, enrichment, and fabrication) and backend (e.g., storage, transportation, reprocessing, and/or disposal) issues would need to be analyzed at some point as well.

\subsection{MATERIAL DEVELOPMENT PHASE}

The analysis work for the material development phase must cover multiple disciplines and plant conditions, as described above. These analysis efforts have been divided into three phases to assist in planning and work control, to help guide the material development process, and overall evaluation of the ATF concept:

- Analysis Phase I: Feasibility - Early feasibility assessment of steady-state neutronics performance and whether or not ATF concept brings benefits for SA scenario(s). This phase supports advancing the concept from a TRL of 2 to 3 .

- Analysis Phase II: Proof of Principle - Extended analyses including other disciplines and behaviors/performance of interest. This will support extending the ATF concept from a TRL of 3 to 4 . 
- Analysis Phase III: Development - With the concept firmly established and determined as reasonable during Analysis Phases I and II, this phase greatly expands the level of detail and applicability for system analyses and further integrates the different disciplines. This phase aids taking the ATF concept from a TRL of 4 to 5, and sets the stage for an LTR analysis effort (see Section 5.2).

Please see the flow diagrams and tables below to see a visual summary of the analyses envisioned to be necessary. A Gantt chart is also provided to show the sequencing and effort levels needed for these analyses. It should be noted that some analyses are best estimate (BE) while others include or rely upon actual peaking factors (PFs) calculated explicitly in the latter analysis phases. Estimated effort levels on the Gantt chart have mostly assumed high-performing national lab R\&D staff performing the activities; the estimates could increase significantly if less-experienced personnel perform the work.

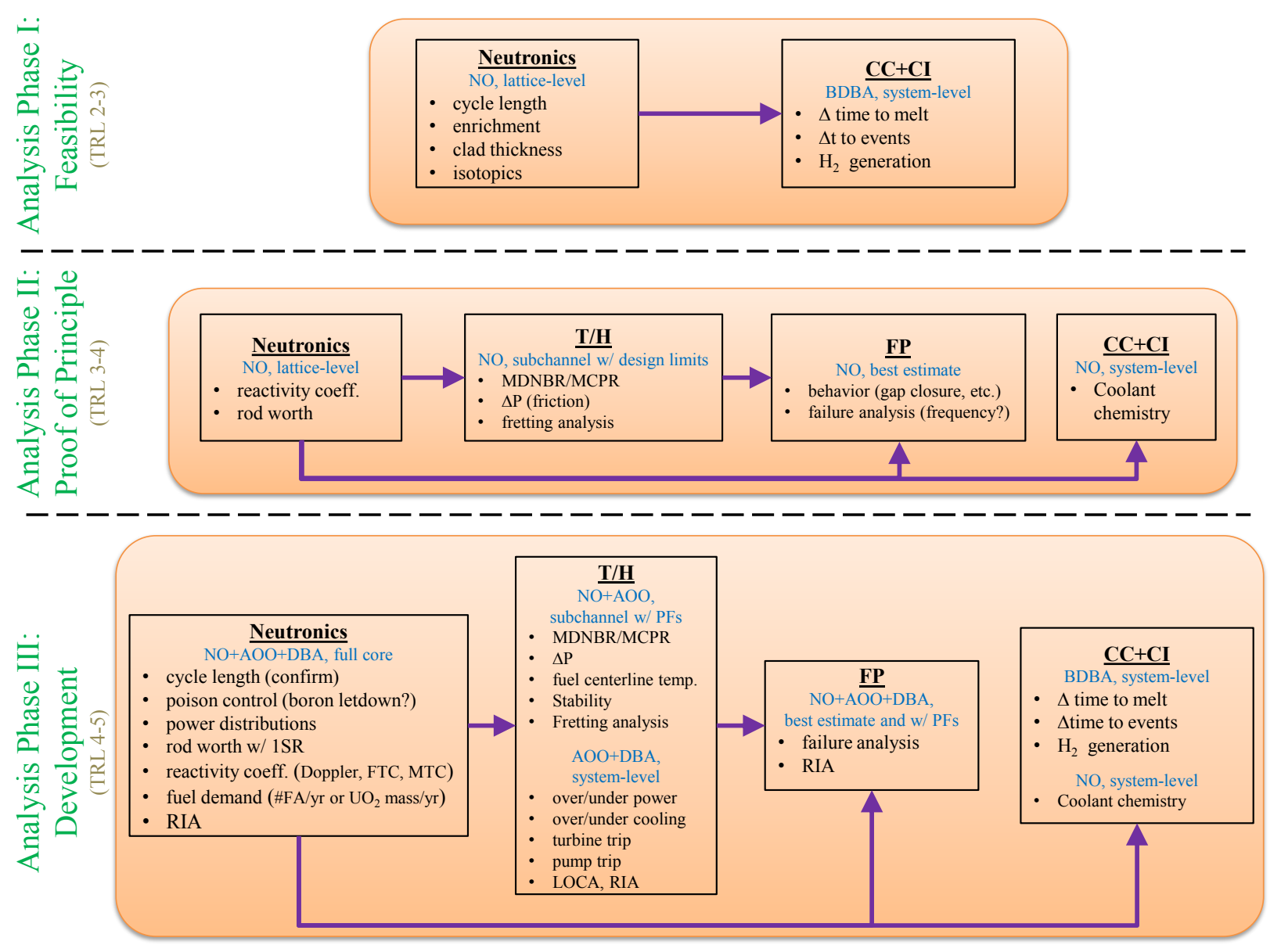




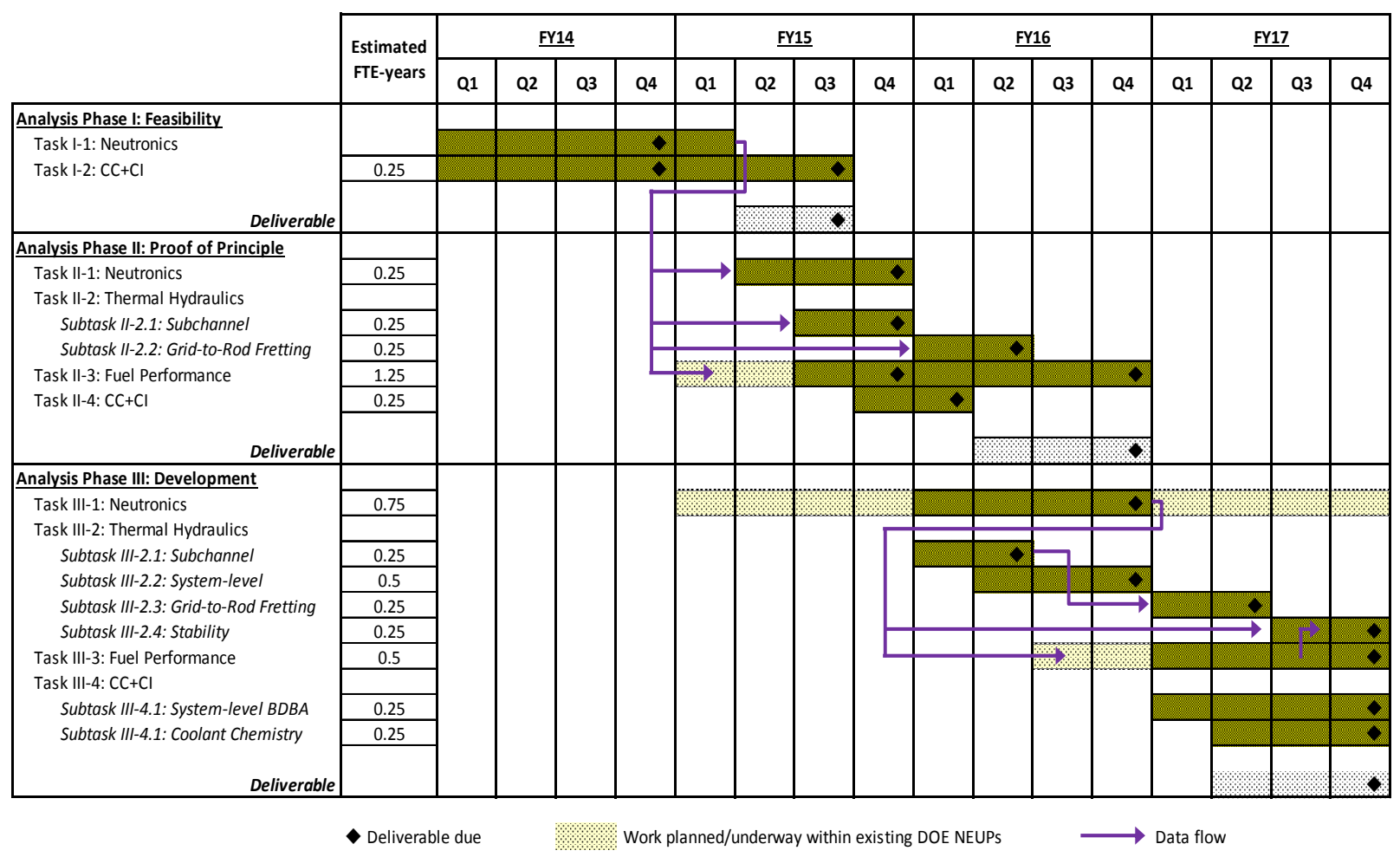

\subsubsection{Analysis Phase I: Feasibility Assessment}

\subsubsection{Task I-1: Neutronics}

Objective:

Assess basic feasibility of FeCrAl-clad $\mathrm{UO}_{2}$ fuel pins in existing LWRs during steady-state normal operations using lattice-level neutronics calculations. These analyses balance the competing desires for speed and quality by minimizing labor effort and calendar time required to provide a reasonable firstorder assessment of the impact on neutronic performance of switching to an ATF fuel and/or cladding concept in existing LWRs. In addition to providing a first-order feasibility assessment, these analyses would establish a reference ATF $\left(\mathrm{UO}_{2} / \mathrm{FeCrAl}\right)$ pin and assembly lattice design.

Work Tasks:

Lattice-level reactor physics calculations will be performed to identify what combinations of uranium enrichment and $\mathrm{FeCrAl}$ cladding thickness are required to match the operational cycle length, in units of Effective Full Power Days (EFPD), obtained from reference Zircaloy/UO $\mathrm{U}_{2}$ fuel pin calculations.

Output:

Estimated ranges for required or desired clad thicknesses and uranium enrichments, as well as a firstorder assessment of overall neutronic feasibility of the ATF concept (i.e., FeCrAl-clad $\mathrm{UO}_{2}$ fuel). These ranges should provide feedback for material technology development (e.g., feedback on clad composition and thickness range). This output will also be used for system-level severe accident analyses being performed in Analysis Phase I.

Time Period:

FY14 Q1 to FY15 Q1. (Note that much of this work is already completed, and a summary report is planned to document the findings of the neutronics work to date). 
Milestone:

Summarize all findings into a written report and incorporate into later Analysis Phase I summary report.

\subsubsection{Task I-2: Core component mechanical and chemical interaction}

Objective:

Assess basic feasibility of $\mathrm{UO}_{2} / \mathrm{FeCrAl}$ fuel assemblies improving system-level performance during SAs by providing increased coping time, increased time before melt, or other such improvements to delay onset of core damage.

Work Tasks:

Add FeCrAl as an independent material to models in SA analysis codes (e.g., MELCOR 1.8.6), fully incorporating Generation $2 \mathrm{FeCrAl}$ properties into MELCOR including thermophysical and oxidation properties. Allow for $\mathrm{FeCrAl}$ to be independently used for various core materials. Perform system-level SA analyses for one or more possible SA progression scenarios for LWRs (e.g., PWR with SBLOCA or BWR with LTSBO or STSBO) using $\mathrm{UO}_{2} / \mathrm{FeCrAl}$ fuel assemblies. Estimate potential gains in coping time, increased time before melt, or other such improvements to delay the onset of fuel degradation and core damage. Other parameters calculated would include the change in time before other events (e.g., lower head failure in a BWR) and hydrogen gas $\left(\mathrm{H}_{2}\right)$ generation as a function of time during the SA scenario(s).

\section{Output:}

These modeling efforts and analyses will provide estimated gains in system-level performance during SA scenarios for $\mathrm{LWRs}$ using $\mathrm{UO}_{2} / \mathrm{FeCrAl}$ assemblies, as well as a first-order assessment of the $\mathrm{UO}_{2} / \mathrm{FeCrAl}$ ATF concept in terms of system-level $\mathrm{CC}+\mathrm{CI}$ performance during BDBAs.

Time Period:

FY14 Q1 to FY15 Q3

Milestone:

Summarize all findings into a written report and incorporate into Analysis Phase I summary report.

Note: Require Generation 2 Alloy Property Estimate/Data

Note: Require input from High Temperature testing and Fuel Degradation testing

Note: Requires basic assembly design (masses, volumes, decay heat distribution)

\subsubsection{Analysis Phase II: Proof of Principle}

\subsubsection{Task II-1: Neutronics}

Objective:

Extend the Analysis Phase I neutronics work by continuing the lattice-level steady-state normal operations calculations of $\mathrm{UO}_{2} / \mathrm{FeCrAl}$ assemblies in existing LWRs to assess reactivity coefficients and lattice reactivity control rod worth. These analyses investigate more detailed behaviors than in Analysis Phase I and help set the foundation for full-core calculations in Analysis Phase III.

Work Tasks:

Lattice-level reactor physics calculations of normal operations will be continued from Analysis Phase I work to assess impacts on reactivity coefficients and lattice reactivity control rod worth. Reactivity coefficients to be investigated include moderator temperature coefficient (MTC), fuel temperature 
coefficient (FTC), Doppler coefficient, void coefficient, and boron coefficient. Lattice reactivity control rod worth provides a first-order estimate of what impact the change in the fuel/cladding system may have on eventual control rod worth calculations performed during full-core analyses in Analysis Phase III, and prepares the ground for any subsequent design changes that may be needed (e.g., use of higher worth control rods). Analyses should also update estimated ranges for cladding thickness and uranium enrichment levels needed to achieve desirable cycle lengths.

Output:

Updated estimated ranges for required or desired clad thicknesses and uranium enrichments, as well as estimated reactivity coefficients. These ranges may provide additional feedback for material technology development (e.g., feedback on clad composition and thickness range). This output will also be used for fuel performance analyses in Analysis Phase II (Task II-3) and provide useful understanding for full-core neutronics calculations in Analysis Phase III (Task III-1).

Time Period:

FY15 Q2 to FY15 Q4

Milestone:

Summarize all findings into a written report and incorporate into later Analysis Phase II summary report.

\subsubsection{Task II-2: Thermal Hydraulics}

\section{Subtask II-2.1: Subchannel}

Objective:

Proof of principle confirmation of thermal performance of assembly design (at assembly level).

Work Tasks:

Subchannel $\mathrm{T} / \mathrm{H}$ analyses will be performed to analyze key thermal performance measures

(MDNBR/MCPR, FCT, etc.) and key hydraulic performance measures (pressure drop, axial forces) for fuel assemblies employing $\mathrm{FeCrAl}$ cladding. It must be ensured that all values are within acceptable design limits.

\section{Output:}

Acceptance and/or refinement of lattice design, as well as guidance on assembly weight and surface roughness. Some of this output will be used to establish input conditions for Analysis Phase II fuel performance work (Task II-3).

Time Period:

FY15 Q3 to FY15 Q4

Milestone:

Summarize all findings into a written report and incorporate into later Analysis Phase II summary report.

\section{Subtask II-2.2: Grid-to-Rod Fretting}

Objective:

Proof of principle investigation of grid-to-rod fretting (GTRF) potential of FeCrAl cladding. These analyses need not be exhaustive or overly complicated but they should provide useful feedback. 
Work Tasks:

Modal analysis will be performed on segments of the baseline FeCrAl cladding concept. Potential excitation frequencies and displacements will be evaluated. The analyses, coupled with material properties (e.g. surface hardness), will provide for a comparison against the baseline Zircaloy cladding.

Output:

Acceptance and/or suggested refinement of lattice design and material properties (grid spacing, cladding thickness, surface hardness, stiffness).

Time Period:

FY16 Q1 to FY16 Q2

Milestone:

Summarize all findings into a written report and incorporate into later Analysis Phase II summary report.

\subsubsection{Task II-3: Thermo-mechanical fuel performance}

Objective:

Provide proof-of-principle demonstration of modeling the thermo-mechanical fuel performance and behavior of a $\mathrm{UO}_{2} / \mathrm{FeCrAl}$ fuel/cladding pin for $\mathrm{NO}$ conditions in existing LWRs using best estimate (BE) numbers obtained from the neutronics and T/H areas (Tasks II-1 and II-2).

Work Tasks:

Develop material models and engineering-scale models for fuel performance models for a $\mathrm{UO}_{2} / \mathrm{FeCrAl}$ fuel/cladding pin in existing LWRs during NO conditions. Develop qualitative and quantitative understanding of how the behavior predicted for $\mathrm{UO}_{2} / \mathrm{FeCrAl}$ fuel pins differs from reference $\mathrm{UO}_{2} /$ Zircaloy fuel pins and assess whether these behavioral differences (e.g., gap closure rates and volumetric swelling as compared to axial growth under irradiation) are likely to have performance or operational impacts (e.g., changes to allowable power ramp rates for reactor startup or likely changes to fuel failure frequencies). Using input conditions obtained from neutronics and $\mathrm{T} / \mathrm{H}$ calculations in Analysis Phase II (Tasks II-1 and II-2), perform failure analyses to assess whether fuel cladding design limits are likely to be exceeded (e.g., stress or strain limits) for $\mathrm{UO}_{2} / \mathrm{FeCrAl}$ fuel pins in $\mathrm{LWRs}$ during steady-state NO conditions. If possible, estimate BE failure probabilities and compare them to reference $\mathrm{UO}_{2} /$ Zircaloy fuel pins in those same conditions.

\section{Output:}

This task should result in a conceptual understanding of behavior for $\mathrm{UO}_{2} / \mathrm{FeCrAl}$ fuel pins and a preliminary assessment of whether fuel cladding design limits are likely to be exceeded by $\mathrm{UO}_{2} / \mathrm{FeCrAl}$ fuel in LWRs during NO conditions.

Time Period:

FY15 Q3 to FY16 Q4

\section{Milestone:}

Summarize all findings into a written report and incorporate into Analysis Phase II summary report. 


\subsubsection{Task II-4: Core component mechanical and chemical interaction}

Objective:

Estimate the level of impact on coolant chemistry issues introduced by using FeCrAl cladding instead of Zircaloy in existing LWRs under NO conditions at the system-level and establish proof of principle level confirmation that no insurmountable coolant chemistry issues exist.

Work Tasks:

Perform preliminary coolant chemistry assessments and screening analyses to estimate the first-order impacts of switching from Zircaloy cladding to $\mathrm{FeCrAl}$ cladding for existing LWRs in NO conditions.

Output:

Proof of principle acceptable of coolant chemistry performance of FeCrAl cladding in LWR water chemistries and environments.

Time Period:

FY15 Q4 to FY16 Q1

Milestone:

Summarize all findings into a written report and incorporate into later Analysis Phase II summary report.

\subsubsection{Analysis Phase III: Development}

\subsubsection{Task III-1: Neutronics}

Objective:

Confirm findings from Analysis Phases I and II and examine neutronic performance of an LWR core using $\mathrm{UO}_{2} / \mathrm{FeCrAl}$ fuel assemblies in much greater detail than previously accomplished using full-core neutronics analyses for existing LWRs under NO, AOO, and DBA conditions.

Work Tasks:

Perform full-core neutronics analyses of LWRs under NO, AOO, and DBA conditions to accomplish multiple objectives including: confirm desirable cycle length for baseline values of clad thickness and uranium enrichment; investigate excess reactivity and power shaping control using poisons including soluble boron in the coolant (i.e., boron letdown curves) and local poison loading such as Integral Fuel Burnable Absorbers (IFBAs) or Wet Annular Burnable Absorbers (WABAs); determine impact of $\mathrm{UO}_{2} / \mathrm{FeCrAl}$ fuel assemblies on assembly-level and pin-level power distributions; examine rod bank worth in the core with one stuck rod assembly; calculate full-core reactivity coefficients (e.g., MTC and FTC); estimate fuel demand in terms of the number of fresh fuel assemblies needed per year and/or the feed $\mathrm{UO}_{2}$ mass needed per year. In order to cover potentially limiting DBAs, perform analyses to support an assessment of behavior and performance during a reactivity-insertion accident (RIA).

Output:

Results will include confirmed baseline values for clad thickness, uranium enrichments, and cycle length. Power distributions will be produced for use throughout all analyses in Analysis Phase III work. Reactivity coefficients, rod worth, cycle length and fuel demand will help support economic and subsequent analyses (e.g., Section 5.2 and Section 6) .

Time Period:

FY16 Q1 to FY16 Q4 
Milestone:

Summarize all findings into a written report and incorporate into later Analysis Phase III summary report.

\subsubsection{Task III-2: Thermal Hydraulics}

\section{Subtask III-2.1: Subchannel}

Objective:

Assembly-level analysis of thermal performance.

Work Tasks:

Analyze key thermal performance measures (MDNBR/MCPR, FCT, etc.) and key hydraulic performance measures (pressure drop, axial forces) for assembly employing FeCrAl over a range of NO, AOO, DBAs. Ensure values are within acceptable limits.

Output:

Thermal performance history for fuel performance and reactivity calculations.

Time Period:

FY16 Q1 to FY16 Q2

Milestone:

Summarize all findings into a written report and incorporate into later Analysis Phase III summary report.

\section{Subtask III-2.2: System-level}

Objective:

System-level analysis of thermal performance during NO, AOO, DBAs.

Work Tasks:

Add $\mathrm{FeCrAl}$ as an independent material in systems code, fully integrating Generation II ATF FeCrAl properties and oxidation characteristics into systems code. Analyze the LWR design, with respect to key thermal performance criteria, for $\mathrm{NO}$ as well as AOO and DBA transients. The analysis will assess the concept in relation to the existing reactor systems and equipment set points. The gains in thermal performance metrics (time to fuel failure during DBAs) will be quantified.

Note: Require Generation II ATF FeCrAl Alloy Property Estimate/Data

Output:

System level thermal performance for fuel performance and criticality calculations.

Time Period:

FY16 Q2 to FY16 Q4

Milestone:

Summarize all findings into a written report and incorporate into later Analysis Phase III summary report.

\section{Subtask III-2.3: Grid-to-Rod Fretting}

Objective:

Expand upon the work in Analysis Phase II and assess whether $\mathrm{UO}_{2} / \mathrm{FeCrAl}$ fuel pins are likely to exhibit significantly different grid-to-rod fretting (GTRF) behavior than reference $\mathrm{UO}_{2} /$ Zircaloy fuel pins. 
Work Tasks:

Perform simple GTRF and wear analyses for NO and AOO conditions with power peaking factors if needed. Compare results for $\mathrm{UO}_{2} / \mathrm{FeCrAl}$ fuel pins or assemblies to the results from reference $\mathrm{UO}_{2}$ /Zircaloy fuel assemblies. This work expands upon GTRF assessment from Analysis Phase II

(Section 6.1.2.2) by using updated assumptions for $\mathrm{UO}_{2} / \mathrm{FeCrAl}$ pin and assembly designs as well as more detailed results from Analysis Phase III neutronics calculations (Section 6.1.3.1).

Output:

Assessment of GTRF issues in $\mathrm{UO}_{2} / \mathrm{FeCrAl}$ fuel pins or assemblies to ensure proper fuel performance.

Time Period:

FY16 Q3 to FY16 Q4

Milestone:

Summarize all findings into a written report and incorporate into later Analysis Phase III summary report.

\section{Subtask III-2.4: Stability (for BWRs)}

Objective:

Stability analysis for BWR NO, AOOs, and DBAs.

Work Tasks:

Specific for BWRs, perform stability analysis to assess stability regimes for assembly design.

Output:

Confirmation/design revision of FeCrAl ATF assembly design.

Time Period:

FY17 Q3 to FY17 Q4

Milestone:

Summarize all findings into a written report and incorporate into Analysis Phase III summary report.

\subsubsection{Task III-3: Thermo-mechanical Fuel Performance}

Objective:

Assess performance of $\mathrm{UO}_{2} / \mathrm{FeCrAl}$ fuel pins in existing LWRs during $\mathrm{NO}$ and $\mathrm{AOO}$ conditions using best estimate values and with peaking factors from the whole core neutronic analysis completed in the earlier phases of work.

Work Tasks:

Improve material models and engineering-scale models for $\mathrm{UO}_{2} / \mathrm{FeCrAl}$ fuel/cladding pin as needed. Using input conditions obtained from neutronics and $\mathrm{T} / \mathrm{H}$ calculations, perform failure analyses to assess whether fuel cladding design limits are likely to be exceeded (e.g., stress or strain limits) for $\mathrm{UO}_{2} / \mathrm{FeCrAl}$ fuel pins in LWRs during $\mathrm{NO}$ and $\mathrm{AOO}$ conditions. If possible, estimate predicted failure probabilities and compare them to reference $\mathrm{UO}_{2} /$ Zircaloy fuel pins in those same conditions. In order to cover potentially limiting DBAs, perform analyses to support an assessment of behavior and performance during a reactivity-insertion accident (RIA).

Output:

An improved assessment of whether fuel cladding design limits are likely to be exceeded for $\mathrm{UO}_{2} / \mathrm{FeCrAl}$ fuel pins in LWRs during NO and AOO conditions. 
Time Period:

FY17 Q1 to FY17 Q4

Milestone:

Summarize all findings into a written report and incorporate into Analysis Phase III summary report.

\subsubsection{Task III-4: Core Component and Chemical Interaction}

\section{Subtask III-4.1: System-level BDBA}

Objective:

Quantify gains provided by FeCrAl ATF concept, using explicit values/analyses from the whole core neutronics, and thermo-mechanical fuel performance completed in the earlier phases.

Work Tasks:

Analyze key severe accident metrics (e.g., margin in time to key accident stages [melting, relocating, loss of primary containment, off-site release], combustible gas generation). Analysis will be performed at a whole system-level to include the integral effects of multiple systems and phenomena. The analysis will include multiple severe accident scenarios representative of the potential spectrum. The analysis should identify any differences/benefits in severe accident mitigation actions that may require further attention.

Output:

Quantified gains provided by FeCrAl ATF concept and SAMG guidance.

Time Period:

FY17 Q1 to FY17 Q4

Milestone:

Summarize all findings into a written report and incorporate into Analysis Phase III summary report.

\section{Subtask III-4.2: Coolant Chemistry}

Objective:

Update the coolant chemistry assessment, using explicit pin power histories from the whole core neutronics and $\mathrm{T} / \mathrm{H}$ analyses.

Work Tasks:

Perform coolant chemistry calculations and screening analyses to estimate the impacts of switching from Zircaloy cladding to FeCrAl cladding for existing LWRs in NO conditions.

Output:

Proof of principle acceptable of coolant chemistry performance of FeCrAl cladding in LWR water chemistries and environments.

Time Period:

FY17 Q2 to FY17 Q4

Milestone:

Summarize all findings into a written report and incorporate into Analysis Phase III summary report. 


\subsection{LTR ANALYSIS}

As stated previously, the purpose of this TIP and therefore the analysis program outlined in Section 5 is not design and licensing work to support LTR insertion into a commercial LWR in the US but rather to provide confidence in the $\mathrm{UO}_{2} / \mathrm{FeCrAl}$ ATF concept before significant investments of time and money are made for licensing efforts. The results from these analyses should be documented and shared with the licensee to support their licensing analyses, but LTR analysis would need to be performed separately by the reactor licensee in conjunction with the vendor using approved methodologies and codes and submitted to the NRC by the licensee of the reactor in question. 


\section{ECONOMICS}

Generally in any economic evaluation of a production process, the 'unit cost' is calculated. In terms of electricity generation from nuclear energy, this is measured in cents/kWh i.e., the unit cost of electricity. Therefore, when considering the economic cost benefit or detriment of a new fuel such as an ATF, the impact on both the numerator (i.e. the cost of fuel production) and denominator (i.e., the impact on electricity production) need to be evaluated.

\subsection{FUEL PRODUCTION COSTS}

The production of the fuel has a number of key components that effect the overall cost in terms of $\$ / \mathrm{kg}$, or \$/assembly finished fuel. Therefore, the following will need to be evaluated:

1. Impact on raw materials requirements e.g., ore, enrichment, etc.

2. Fuel pellet manufacture

3. Fuel pin, and assembly components

4. Construction of finished fuel assembly e.g., more complex, additional heterogeneity in fuel

5. Inspection of finished fuel assembly, including quality assurance

6. Impact on fuel plant throughput e.g., enrichment constraints if $>5 \mathrm{wt} . \% \mathrm{U}-235$

\subsection{ELECTRICITY PRODUCTION}

As some of the studies on ATFs have already shown, there can be a reactivity, and therefore a cycle length penalty. The true extent of the impact on cycle length can only be evaluated with any confidence once the whole core analyses have been completed (see work scope above). However, a shorter cycle length does not reflect a loss of electricity production - it simply means that in a given number of years of operation, there are more cycles of operation, and therefore more outages, and therefore the capacity factor is reduced. It is the effect on capacity factor that requires an economic analysis. This includes:

1. Effect of reduction in cycle length due to reactivity penalty in the fuel

2. Reduction in thermal margins, and hence operational flexibility

3. Impact on outage times caused by any additional handling and inspection requirements due to ATF e.g., non-destructive PIE, handling constraints such as enrichment constraints if $>5 \mathrm{wt} . \% \mathrm{U}-$ 235 etc.

\subsection{ADDITIONAL CONSIDERATIONS}

Further economic considerations could include:

1. Development and deployment cost comparisons

2. Licensing costs

3. Waste management, including spent fuel issues, and fuel production e.g., purification of $\mathrm{Zr}$ claddings (removal of Hf) is a chemically intense process - how do the others compare?

Activity and Milestones:

FY15

1. Evaluation on fuel production costs (COMPLETE)

2. Evaluation on electricity production: (COMPLETE)

3. Evaluation of additional considerations (COMPLETE) 


\section{REFERENCES}

[1] Advanced Fuels Campaign - Light Water Reactor - Accident Tolerant - Fuel Performance Metrics, February 2014, INL/EXT-13-29957, FCRD-FUEL-2013-000264

[2] G. Bonny, D. Terentyev, L. Malerba, On the $\alpha-\alpha^{\prime}$ miscibility gap of $\mathrm{Fe}-\mathrm{Cr}$ alloys, Scripta Materialia, 59 (2008) 1193-1196.

[3] J. P. Foster and T. M. Karlsen, "Update of Irradiation Creep and Irradiation Stress Relaxation of 316 and 304L Stainless Steel, HWR-1047," OECD Halden Reactor Project2013.

[4] Y. Katoh, A. Kohyama, D. Gelles, Swelling and dislocation evolution in simple ferritic alloys irradiated to high fluence in FFTF/MOTA, Journal of Nuclear Materials, 225 (1995) 154-162

[5] E.A. Little, D.A. Stow, Void-swelling in irons and ferritic steels, Journal of Nuclear Materials, 87 (1979) 25-39.

[6] Y.H. Leea, T.S. Byun, A Comparative Study on the Wear Behaviors of Cladding Candidates for Accident-Tolerant Fuel, JNM-D-14-01186, NuMat 2014 Conference Papers.

[7] R. B. Rebak In Alloy Selection for Accident Tolerant Fuel Cladding in Commercial Light Water Reactors, TMS 2014, San Diego, CA, Feb 16-20; San Diego, CA, 2014

[8] M. Steinbrück; M. Große; L. Sepold; J. Stuckert, Nuclear Engineering and Design 2010, 240 (7), 1714-1727

[9] D. Tomalin; R. Adamson; R. Gangloff, Zirconium in the Nuclear Industry 1979, 122-144.

[10] D. Olander; Y. S. Kim; W.-E. Wang; S. K. Yagnik, Journal of nuclear materials 1999, $270(1), 11-20$ 